\title{
Catalysis on Solid Acids: Mechanism and Catalyst Descriptors in Oligomerization Reactions of Light Alkenes
}

\author{
Michele L. Sarazen ${ }^{1}$, Eric Doskocil ${ }^{2}$ and Enrique Iglesia ${ }^{1 *}$ \\ ${ }^{1}$ Department of Chemical and Biomolecular Engineering \\ University of California, Berkeley \\ Berkeley, CA, 94720 \\ ${ }^{2}$ BP Products North America Inc. \\ 150 West Warrenville Rd.
}

Naperville, IL 60563

*to whom correspondence should be addressed: iglesia@berkeley.edu 


\begin{abstract}
This study addresses fundamental descriptions of confinement and acid strength effects on stability for transition states and intermediates involved in alkene oligomerization on solid acids. Kinetic and infrared data and theoretical treatments that account for dispersive interactions show that turnover rates $\left(\right.$ per $\mathrm{H}^{+}$) on aluminosilicates and heterosilicates with microporous voids (TON, MFI, BEA, FAU) and on mesoporous acids (amorphous silica-alumina, dispersed polyoxometalates) reflect the free energy of $\mathrm{C}-\mathrm{C}$ bond formation transition states referenced to gaseous alkenes and bound alkene-derived precursors present at saturation coverages. These free energy barriers decrease as the size of confining voids decrease in aluminosilicates containing acid sites of similar acid strength and approach bimolecular transition state (TS) sizes derived from density functional theory (DFT) for propene and isobutene reactants. Such TS structures are preferentially stabilized over smaller bound precursors via contacts with the confining framework. These effects of size, typically based on heuristic geometric analogies, are described here instead by the dispersive component of DFT-derived energies for TS and intermediates, which bring together the effects of size and the shape, for different framework voids and TS and precursor structures derived from alkenes of different size; these organic moieties differ in "fit" within voids but also in their proton affinity, as a result of the ion-pair character of TS structures. The larger charge in TS structures relative to their alkene-derived precursors cause free energy barriers to decrease as conjugate anions become more stable in stronger acids. Consequently, oligomerization rate constants decrease exponentially with increasing deprotonation energy on unconfined acid sites in polyoxometalates and silica-alumina and on confined sites within MFI frameworks with $\mathrm{Al}, \mathrm{Ga}, \mathrm{Fe}$, or B heteroatoms. Reactivity descriptions based on geometry or acid strength are replaced by their more relevant energetic descriptors-van der Waals confinement energies, proton affinities of organic molecules, and deprotonation energies-to account for reactivity, here for different reactants on diverse solid acids, but in general for acid catalysis.
\end{abstract}




\section{Introduction}

Light alkene oligomerization is an attractive route for the synthesis of chemical feedstocks and transportation fuels from undervalued precursors [1-4]. Turnover rates (per proton) for reactions of hydrocarbons and oxygenates on solid Brønsted acids depend sensitively on the size and shape of the molecular-sized voids that contain the active protons in microporous aluminosilicates [5-7]. The strength of the acid sites also influences reactivity when ion-pair transition states differ in charge from their adsorbed precursor species [8-11]. Acid forms of zeolites and mesoporous aluminosilicates contain acid sites of similar strength [12], but they reside within confining voids of very different size and connectivity, thus creating diverse reactivities and selectivities, in spite of their similar acid strength [6]. Such effects reflect the preferential solvation of specific molecules or transition states through van der Waals interactions, as a consequence of their different ability to contact the surrounding framework.

The isomorphous substitution of different heteroatoms (Al, Ga, Fe, B) into a given silicate framework preserves a similar confining environment, while varying acid strength [11,13]; $\mathrm{SiO}_{2}$-supported Keggin polyoxometalates (POM) clusters with $\mathrm{W}$-addenda atoms and different central atoms contain sites of diverse acid strength; these acid sites are significantly stronger than those in aluminosilicates [14], but lack the molecular confinement properties of microporous solids. These materials allow a rigorous assessment of how the stability of the conjugate anion, the pre-eminent feature of the deprotonation energies that determine acid strength, influences the free energy of the relevant transition states and adsorbed precursors. Extensive studies of alkene oligomerization catalysis have broadly explored the reactive and selective properties of acid catalysts [1-3,13,15-19], but without the broad range of materials or the systematic and purposeful variations in void environment and acid strength, the detailed 
measurements and mechanistic interpretation of turnover rates, or the theoretical treatments that we bring together in the present study.

We find that the addition of alkenes to alkene-derived alkoxides is the sole kineticallyrelevant step in propene and isobutene oligomerization turnovers and that the adsorptiondesorption steps of alkene reactants and products are quasi-equilibrated. The nature of the alkene-derived species that is most abundant on the surface intermediate remains uncertain, especially for isobutene-derived species, in which steric effects may disfavor the formation of covalently-bound butoxides [20-23]. The absence of intact or perturbed O-H stretches [24,25] in infrared spectra during oligomerization of propene or isobutene on TON and MFI, suggest the prevalence of bound alkoxides at near saturation coverages during catalysis. Density functional theory (DFT) treatments of the stability of the transition states and bound intermediates that mediate oligomerization reactions implicate the formation of the $\mathrm{C}-\mathrm{C}$ bonds, via reactions of gaseous alkenes with bound alkoxides, as the sole kinetically-relevant elementary step.

First-order rate constants (per $\mathrm{H}^{+}$) were found to be independent of $\mathrm{Al}$ content or proton density for a given framework structure on zeolites; therefore, measured rates are not affected by any diffusional artifacts and the location of the protons must remain the same at all Al contents. Rate constants increased monotonically as the aluminosilicate voids became smaller (FAU, MFI, BEA, TON), also observed for other reactions, such as monomolecular alkane cracking [26], dimethyl ether homologation [27] and methanol dehydration [5]. Such trends reflect the preferential stabilization of bimolecular transition states that are larger than their alkene-derived precursors and which consequently contact the confining framework more effectively. These effects are quantified here using the dispersive component of DFT-derived energies [28,29], an energy descriptor that replaces heuristic geometric arguments typically used to account for 
confinement effects. Rate constants also increased on a given catalyst as the reactant, and thus the transition state, increased in size. Such effects reflect a combination of the more stable nature of larger carbenium ions and their more effective van der Waals contacts with frameworks. The effectiveness of such contacts is enhanced, especially for larger transition states, by local distortions of the zeolite framework, which compensate the energy required to distort stable crystal lattices by allowing stronger van der Waals interactions between transition states and their confining voids.

Oligomerization rate constants decreased exponentially with increasing deprotonation energies (DPE), a rigorous descriptor of acid strength, for acid sites within mesoporous silicas ( $\mathrm{POM}\left(\mathrm{H}_{3} \mathrm{PW}_{12} \mathrm{O}_{40}, \mathrm{H}_{4} \mathrm{SiW}_{12} \mathrm{O}_{40}\right)$; silica-alumina (SiAl)) or microporous heterosilicates (X-MFI; $\mathrm{X}=\mathrm{Al}^{3+}, \mathrm{Ga}^{3+}, \mathrm{Fe}^{3+}, \mathrm{B}^{3+}$ ), as a result of the stronger effects of conjugate anion stability on ionpair transition states relative to the alkene-derived bound species. These preferential effects of acid strength on transition state stability, combined with the additive effects of confinement, provide predictive guidance for the design of solid acids with the most appropriate strength and proton location, thus allowing accurate extensions to molecules that differ in size and structure from propene and isobutene, the reactants used here to illustrate these concepts.

\section{Experimental Methods}

\subsection{Materials used and assessment of their number of accessible protons}

BEA, MFI (all X-MFI), TON, FAU and mesoporous silica-alumina (provenance, Si/Al ratio in Table 1) were obtained from commercial sources with protons, ammonium, or structuredirecting agents (used in their synthesis) as balancing cations. Si and Al (Table 1a) contents were measured by inductively-coupled plasma optical emission spectroscopy. All samples were treated in flowing dry air $\left(2.5 \mathrm{~cm}^{3} \mathrm{~g}^{-1} \mathrm{~s}^{-1}\right.$, zero grade, Praxair) by heating to $818 \mathrm{~K}$ (at $0.0167 \mathrm{~K} \mathrm{~s}^{-}$ 
${ }^{1}$ ) and holding for $3 \mathrm{~h}$ to remove any synthetic residues, decompose $\mathrm{NH}_{4}{ }^{+}$cations, remove ambient moisture, and convert all samples to their H-form. These samples were then exchanged with $\mathrm{NH}_{4}{ }^{+}$using aqueous solutions of $0.1 \mathrm{M} \mathrm{NH}_{4} \mathrm{NO}_{3}\left(300 \mathrm{~cm}^{3}\right.$ g-zeolite ${ }^{-1}, 98 \%$ ACS Reagent, Sigma-Aldrich) at $353 \mathrm{~K}$ for $2 \mathrm{~h}$ and the solids isolated by centrifugation. This procedure was carried out thrice and samples were finally rinsed with deionized water $\left(500 \mathrm{~cm}^{3} \mathrm{~g}^{-1}\right)$ and isolated by filtration. These protocols led to starting materials in a common $\mathrm{NH}_{4}$-form, which is more stable for storage and also allows the number of protons to be determined from the $\mathrm{NH}_{3}$ evolved during thermal treatment.

The number of protons was measured from the amount of $\mathrm{NH}_{3}$ evolved using the $\mathrm{NH}_{4}$ form of zeolites $(0.05-0.13 \mathrm{~g})$ placed onto a quartz frit held within a quartz tube and heating to $923 \mathrm{~K}$ (at $\left.0.833 \mathrm{~K} \mathrm{~s}^{-1}\right)$ in a flowing mixture of $\operatorname{Ar}\left(0.83 \mathrm{~cm}^{3} \mathrm{~g}^{-1} \mathrm{~s}^{-1}, 99.999 \%\right)$ in He. A Si-coated stainless steel capillary held at $420 \mathrm{~K}(0.254 \mathrm{~mm}$ i.d., $183 \mathrm{~cm}$ length $)$ was placed immediately below the sample and connected to a mass spectrometer (MKS Spectra Minilab) to measure $\mathrm{NH}_{3}$ (17, $16 \mathrm{amu}), \mathrm{H}_{2} \mathrm{O}(18,17 \mathrm{amu})$ and $\mathrm{Ar}(40 \mathrm{amu})$ concentrations in the effluent stream.

Keggin POM clusters were dispersed onto mesoporous colloidal silica (Cab-O-Sil HS-5; $310 \mathrm{~m}^{2} \mathrm{~g}^{-1} ; 1.5 \mathrm{~cm}^{3} \mathrm{~g}^{-1}$ pore volume) [8]. The number of protons in Keggin POM clusters and amorphous silica-alumina $(\mathrm{SiAl})$ was measured by titration with a non-coordinating amine $(2,6-$ di-tert-butylpyridine) during 2-methyl pentane isomerization [8] and propene oligomerization reactions, respectively (Table 1b). Turnover rates for both reactions were fully suppressed by the addition of the hindered titrant, indicating that both reactions occur only on Brønsted acids sites. Agreement between both methods of proton enumeration has been previously described for methanol dehydration [11]. 
Table 1. Material information and properties for the heterosilicates (a; source, Si/T ratio and proton counts) and polyoxometalate (POM) clusters (b; loading, density and proton counts) used in this study.

\begin{tabular}{|c|c|c|c|c|}
\hline \multirow{18}{*}{ a } & Sample & \multicolumn{2}{|c|}{$(* \mathbf{T}=\mathrm{Al}$ unless otherwise noted $)$} & d) $\mathbf{H}^{+} / \mathbf{T} *$ Ratio \\
\hline & BEA & Zeolyst & 11.8 & $0.39^{2}$ \\
\hline & BEA & Zeolyst & 43 & $0.98^{2}$ \\
\hline & MFI & Zeolyst & 16.6 & $0.52^{2}$ \\
\hline & MFI & Zeolyst & 29.2 & $0.72^{2}$ \\
\hline & MFI & Zeolyst & 43.8 & $0.89^{2}$ \\
\hline & MFI & Zeolyst & 173 & $0.64^{2}$ \\
\hline & MFI & Sud-Chemie & 14 & $0.71^{2}$ \\
\hline & MFI & Tri-Cat & 25 & $0.35^{2}$ \\
\hline & MFI & $\mathrm{BP}$ & 26 & $0.80^{2}$ \\
\hline & Ga-MFI & $\mathrm{BP} ;[30]$ & 45 & $0.86^{2}$ \\
\hline & Fe-MFI & {$[11]$} & 61 & $0.86^{3}$ \\
\hline & B-MFI & $\mathrm{BP} ;[31]$ & 43 & $0.77^{2}$ \\
\hline & TON & $\mathrm{BP}^{4}$ & 24 & $0.40^{2}$ \\
\hline & TON & $\mathrm{BP}^{4}$ & 39 & $0.55^{2}$ \\
\hline & TON & $\mathrm{BP}^{4}$ & 49 & $0.50^{2}$ \\
\hline & LZ-210 & Engelhard & 7.5 & $0.37^{2}$ \\
\hline & Silica-Alumina & Sigma-Aldrich & 5.5 & $0.25^{5}$ \\
\hline \multirow[t]{3}{*}{$\mathrm{b}$} & Sample & $\begin{array}{c}\text { POM content on } \\
\text { Silica } \\
(w t . \%)\end{array}$ & 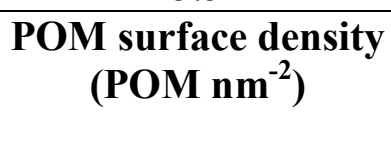 & Protons $\left(\mathrm{H}^{+} / \mathrm{POM}\right)^{5}$ \\
\hline & $\mathrm{H}_{3} \mathrm{PW}_{12} \mathrm{O}_{40}$ & 5 & 0.04 & 0.72 \\
\hline & $\mathrm{H}_{4} \mathrm{SiW}_{12} \mathrm{O}_{40}$ & 5 & 0.04 & 1.6 \\
\hline
\end{tabular}

from elemental analysis (ICP-OES).

${ }^{2}$ from decomposition of $\mathrm{NH}_{4}^{+}$exchanged sample.

${ }^{3}$ from [11].

${ }^{4}$ prepared according to patents [32,33].

5 from 2,6-di-tert-butylpyridine titration.

\subsection{Alkene oligomerization turnover rates}

All samples (Table 1) were pelleted, crushed, and sieved to retain 180-250 $\mu \mathrm{m}$ aggregates. Alkene conversion turnover rates were measured on samples (15-100 mg) placed within a tubular reactor with plug-flow hydrodynamics (316 stainless steel; $12 \mathrm{~mm} \mathrm{I.D.).} \mathrm{The}$ temperature was set using a three-zone resistively-heated furnace (Applied Test Systems Series 3210; Watlow controllers; 96 Series) and measured with a K-type thermocouple held within an internal concentric thermowell placed with its tip in the axial center point of the packed bed. 
Microporous aluminosilicates and other heterosilicates in their $\mathrm{NH}_{4}$-form were treated before catalytic rate measurements in a $5 \% \mathrm{O}_{2}$ in He stream $\left(83.3 \mathrm{~cm}^{3} \mathrm{~g}^{-1} \mathrm{~s}^{-1}\right.$, Praxair) by heating to 818 $\mathrm{K}$ (at $0.025 \mathrm{~K} \mathrm{~s}^{-1}$ ) and holding for $3 \mathrm{~h}$ to convert the $\mathrm{NH}_{4}{ }^{+}$to $\mathrm{H}^{+}$, and then cooled to $503 \mathrm{~K}$. Keggin POM clusters (H-form) were treated in flowing He $\left(50 \mathrm{~cm}^{3} \mathrm{~g}^{-1} \mathrm{~s}^{-1} ; 99.999 \%\right.$, Praxair) by heating to $503 \mathrm{~K}$ (at $0.083 \mathrm{~K} \mathrm{~s}^{-1}$ ) to remove adsorbed moisture. Propene (99.9\%, Praxair) or isobutene (99.9 \%, Praxair) were introduced into a He stream (99.999 \%, Praxair) at the molar rates required to achieve the desired alkene pressure; the total system pressure was maintained using a dome-loaded regulator (Tempresco). The effluent was transferred through lines held above $373 \mathrm{~K}$ into a gas chromatograph (Agilent 6890) to measure reactant and product concentrations using flame ionization detection after chromatographic separation with a methyl silicone capillary column (Agilent HP-1 column, $50 \mathrm{~m}$ x $0.32 \mathrm{~mm} \times 1.05 \mu \mathrm{m}$ film) where known retention times of hydrocarbon mixtures on similar columns were used for molecular speciation $[34,35]$.

\subsection{Infrared assessment of hydroxyl groups and adsorbed species during catalysis}

Infrared spectra were collected using a Nicolet NEXUS 670 infrared spectrometer equipped with a Hg-Cd-Te (MCT) detector cooled with liquid $\mathrm{N}_{2}$. Self-supported wafers ( 20-40 mg) were sealed within a quartz vacuum infrared cell fitted with $\mathrm{NaCl}$ windows and treated in flowing dry air $\left(20.8 \mathrm{~cm}^{3} \mathrm{~g}^{-1} \mathrm{~s}^{-1}\right.$, zero grade, Praxair) by heating to $818 \mathrm{~K}$ (at $0.033 \mathrm{~K} \mathrm{~s}^{-1}$ ), holding for $3 \mathrm{~h}$, and cooling to reaction temperature in flowing He. Propene ( $99.9 \%$, Praxair) or isobutene (99.9 \%, Praxair) were then introduced into the He flow (99.999 \%, Praxair) at rates

designed to give desired alkene pressures. Spectra were collected with $2 \mathrm{~cm}^{-1}$ resolution and $4000-400 \mathrm{~cm}^{-1}$ by averaging 64 scans.

\subsection{Density functional theory methods}


Periodic density functional theory in the Vienna ab initio Simulation Package (VASP) [36-39] was used to determine optimized structures and energies for stable intermediates and transition states. Wavefunctions were represented by a periodic plane-wave basis set expansion (to a cut-off energy of $396 \mathrm{eV}$ ) and projector-augmented wave (PAW) pseudopotentials were used to describe electron-core interactions [40,41]. Exchange and correlation energies for zeolites were calculated within the generalized gradient approximation using revised PerdewBurke-Ernzerhof (RPBE) functionals [42-44] with dispersive energies and forces calculated by DFT-D3 during each energy minimization [28,29]. Calculations for Keggin POM clusters were done with the revised Perdew-Wang (PW91; [45]) functional in order to be consistent with previous studies $[8-10,14,46]$. A 1 x 1 x 1 Monkhorst-Pack k-point mesh was used to sample the first Brillioun zone in both cases [47].

Minimum energy reaction paths were calculated using nudged elastic band (NEB) methods [48] with structures converged to energies within $1 \times 10^{-4} \mathrm{eV}$ and forces to within 0.3 $\mathrm{eV} \AA^{-1}$ to identify starting structures for TS structures, which were further refined using Dimer methods [49]. Energies were converged self-consistently to $<1 \times 10^{-6} \mathrm{eV}$ for each optimization step and structures were converged until forces on all atoms were $<0.05 \mathrm{eV} \AA^{-1}$. Reactant, product and transition state energies include contributions from electronic energies $\left(\mathrm{E}_{0}\right)$, zeropoint vibrational energies (ZPVE), vibrational free energies $\left(\mathrm{G}_{\mathrm{vib}}\right)$ and translational and rotational free energies $\left(G_{\text {trans }}\right.$ and $\left.G_{\text {rot }}\right)$ for gaseous molecules. ZPVE and $G_{\text {vib values were }}$ determined from the frequencies in optimized structures. Low-frequency modes of weaklybound adsorbates were excluded because of significant inaccuracies in their contributions to free energies. Instead, these modes were incorporated as a fraction (0.7) of the translational and rotational gas phase entropies of alkene analogs from statistical mechanics, a method shown to 
accurately estimate adsorption entropies of adsorbed molecules on oxide surfaces [50].

Keggin POM clusters were described by placing full clusters $(1.1 \mathrm{~nm}$ diameter $)$ at the center of $3 \times 3 \times 3 \mathrm{~nm}^{3}$ unit cells to prevent electronic interactions among neighboring cells. Deprotonation energies (DPE) values are defined as the energy required to remove a proton $\left(\mathrm{H}^{+}\right.$, with energy $\left.\mathrm{E}_{\mathrm{H}^{+}}\right)$from an acid $\left(\mathrm{AH}\right.$, with energy $\left.\mathrm{E}_{\mathrm{AH}}\right)$ to non-interacting distances leaving the isolated conjugate base $\left(\mathrm{A}^{-}\right.$, with energy $\left.\mathrm{E}_{\mathrm{A}_{-}}\right)$:

$D P E=E_{\mathrm{H}^{+}}+E_{\mathrm{A}^{-}}-E_{\mathrm{HA}}$

The DPE values for POM clusters were calculated with secondary alkoxides bound at all but the bridging proton that was removed (Fig. 1; HPW) to account for any effects of the saturation alkoxide coverages present during reaction and inferred from kinetic and infrared data (Section 3.1). On clusters of semiconducting oxides, such bound species influence intracluster binding properties, including DPE values. The isolated nature of the protons in aluminosilicates and their insulating properties as solids renders their properties insensitive to the identity or coverage of species bound at non-vicinal sites. DPE values are therefore reported on bare surfaces as their average value over all oxygen and T-site locations for each zeolite framework [11].

Figure 1. DFT-optimized HPW structure with secondary propoxides at the two nonreacting proton locations [PW-91].

TON, MFI and FAU zeolites were described using five, one and one unit cells (unit cells defined in [51]), respectively, because they contained large and similar numbers of atoms and fully captured the details of the relevant voids, while providing a vacuum region that prevents electronic interactions among chemical species present in periodic images. The following proton locations (as per site numbering convention [51]) were used for the DFT analysis of relevant 
precursors and transition states: Al1-O1(H) in FAU, located in the supercage and the only T-site in FAU; A112-O20(H) in MFI, located at the intersection void of the sinusoid and straight channels, which represents the environment of the 8 of the 12 T-sites in MFI; Al3-O4(H) in TON, which is in the one-dimensional channel, the location of 3 of the 4 T-sites in the framework. Dispersive interactions between the organic atoms of the transition state and the MFI or FAU pores were approximated by transferring the optimized Dimer structure from TON to the aforementioned T-sites in MFI and FAU at similar distances above the T-site and into the voids.

\section{Results and Discussion}

\subsection{Kinetic and spectroscopic assessment of alkene dimerization mechanism}

Alkenes with $i \mathrm{C}$-atoms react on acid catalysts to form dimers $\left(\mathrm{C}_{2 \mathrm{i}}\right)$ and larger oligomers $\left(\mathrm{C}_{3 \mathrm{i}}, \mathrm{C}_{4 \mathrm{i}}\right.$, etc. $)$, via sequential additions of alkenes. The rate of the initial dimerization step equals the rate of propene consumption when propene is predominantly converted to $\mathrm{C}_{6}$ oligomers, as typically observed at lower alkene conversions and pressures. TON, amorphous silica-alumina (SiAl) and silica-supported polyoxometalate $(\mathrm{POM})$ clusters $\left(\mathrm{H}_{3} \mathrm{PW}_{12} \mathrm{O}_{40}\right.$, herein forth denoted as HPW) mostly form dimers ( $>90 \%$ carbon selectivity) and the small rate of $\mathrm{C}_{9}$ formation observed at low conversions $(<5 \%)$ is included into the dimerization rate as it was formed from a dimer. The product distribution on MFI, BEA and FAU is more complex due to concurrent $\beta$ scission reactions [52] and the rate of dimerization is estimated as the total propene consumption rate. The propene dimerization turnover rates (normalized by $\mathrm{H}^{+}$) are proportional to the pressure of propene reactants (10-450 kPa, $503 \mathrm{~K}$ ) on TON, BEA, MFI and FAU zeolites (Fig. 2a) and on HPW and SiAl mesoporous acids (Fig. 2b). Similar first-order kinetic dependences were observed on Ga-MFI, Fe-MFI, B-MFI and on Al-TON and Al-MFI samples with other Si/Al ratios and these data are included in the Supplementary Information (SI; Fig. S1). The 
insensitivity of turnover rates to $\mathrm{Si} / \mathrm{Al}$ ratios (site density) is discussed in Section 3.2. The effects of framework substitution in heterosilicates with MFI structure are discussed in terms of acid strength and deprotonation energies in Section 3.3.

Regressed first-order rate constants (per $\mathrm{H}^{+}$) vary by a factor of $\sim 100$ among these catalysts (Fig. 2c); such large differences in reactivity are evident even among microporous aluminosilicates samples that differ solely in their ability to confine transition states and precursors, but contain acid sites of similar strength [12]. The logarithmic scale in the ordinate of Figure $2 \mathrm{c}$ highlights these large effects of confining structure and acid strength and the expected exponential dependence of rate constants on free energies of activation. The underlying chemical meaning of these effects requires a mechanistic interpretation of these rate constants in the context of the formalism of transition state theory. It also requires a systematic and rigorous description, first in terms of geometries but ultimately in terms of energies, of how van der Waals interactions, as well as the stability of the conjugate anions, influence transition state (TS) structures and the precursors to such structures, as discussed below.

Figure 2. Propene dimerization turnover rates on zeolites (a) (TON: $\bullet$, BEA: $\boldsymbol{\Delta}$, MFI: FAU: $\mathbf{\square})$ and mesoporous samples (b) (HPW: $\mathbf{\square}$, SiAl: $\mathbf{0}$ ) as a function of propene pressure [503 K; $<5 \%$ propene conversion; dashed lines represent linear regression fits]. (c) Fitted first order rate constants on all solid acids.

Theoretical studies on $4 \mathrm{~T}$-atom cluster models have concluded that $\mathrm{C}-\mathrm{C}$ bonds form via reactions of $\mathrm{C}_{2}-\mathrm{C}_{4}$ alkenes with their respective bound alkoxides, instead of via concerted protonation of an alkene followed by $\mathrm{C}-\mathrm{C}$ bond formation between the protonated species and another alkene $[18,53]$. The observed effects of reactant pressure on turnover rates are consistent with the formation of dimers via kinetically-relevant steps in which a gaseous or confined alkene reacts with an alkene-derived adsorbed species bound at protons and present at saturation 
coverages; such adsorbed species may consist of $\pi$-bonded, H-bonded, or protonated alkenes, with the latter consisting of species with two or more possible surface attachments along the alkene backbone (e.g., primary and secondary propoxides from propene; primary and tertiary isobutoxides from isobutene). Such a mechanistic proposal is confirmed here by the alkoxidesaturated surfaces detected by infrared spectroscopy during reaction and by the equilibration among the isomers formed in oligomerization events, which requires, in turn, the concomitant equilibration of their adsorption-desorption steps.

The infrared spectra measured during alkene oligomerization on MFI and TON lack any detectable bands for unperturbed protons, which are evident in both samples before contact with propene. The Brønsted $v(\mathrm{O}-\mathrm{H})$ band, evident in MFI and TON at $\sim 3600 \mathrm{~cm}^{-1}$ [54] (Fig. 3 left, Spectrum a (MFI); Fig. 3 right, Spectrum a (TON); 503 K), disappears upon exposure to propene (10 kPa; Fig. 3 left, Spectrum b (MFI); Fig. 3 right, Spectrum b (TON); 503 K) even at the lowest pressures used in rate measurements $(10 \mathrm{kPa})$. Infrared bands characteristic of $-\mathrm{O}-$ $\mathrm{C}_{\mathrm{n}} \mathrm{H}_{2 \mathrm{n}+1}$ species with sp ${ }^{3} \mathrm{C}$-atoms appear at $1500-1450 \mathrm{~cm}^{-1}[24,20,55]$. The stretches observed at $1365-1370 \mathrm{~cm}^{-1}$ for propene on both MFI and TON are consistent with $v(\mathrm{O}-\mathrm{C})$ features in secondary and primary propoxide species at the T-12 location in MFI and T-3 location in TON (1367-1370 $\mathrm{cm}^{-1}$; Table S1; SI). The complete disappearance of the O-H band, without the concomitant appearance of broad perturbed $\mathrm{OH}$ bands (characteristic of $\pi$ - or H-bonding of the alkene) $[24,25,56]$ provide evidence for the transfer of the protons to the bound alkene and for the formation of covalently-bound alkoxides.

Figure 3. Left: Infrared spectra of MFI $(\mathrm{Si} / \mathrm{Al}=43)$ at $503 \mathrm{~K}$ before contact with propene (a) and in $10 \mathrm{kPa}$ propene (after $0.18 \mathrm{ks}$; b). Right: Infrared spectra of TON ( $\mathrm{Si} / \mathrm{Al}=39)$ at $503 \mathrm{~K}$ in $\mathrm{H}-$ form (a), in $10 \mathrm{kPa}$ propene (after $0.18 \mathrm{ks}$; b) and in $8 \mathrm{kPa}$ isobutene (after $0.18 \mathrm{ks}$; c). 
The hexene dimers formed from propene consist of skeletal and regioisomers in proportions set by their gaseous thermodynamics on all solid acids (TON, MFI, BEA, SiAl, HSiW; 0.01-0.5 fractional propene conversion; 10-400 $\mathrm{kPa}, 503 \mathrm{~K}$ ) [52]. Such equilibration requires facile hydride and methyl shifts in bound alkoxides, but also fast and quasi-equilibrated adsorption-desorption events These hexenes consist of equilibrated regioisomers for all skeletal backbones (2-methylpentenes (2-MP), 3-methylpentenes (3-MP), linear hexenes (n-H) and 2,3dimethylbutenes (23-DMB)); all the skeletal backbones are also present in thermodynamic proportions. These facile interconversion are also evident from the full intramolecular scrambling in all products of $2-{ }^{13} \mathrm{C}$-propene reactions on TON, MFI, SiAl and HSiW (503 K, 2 $\mathrm{kPa} ;[52])$.

These isomer distributions indicate that all alkoxides are in equilibrium with their respective reactant and product alkenes and that fast hydride shifts lead to alkoxides with attachments to the surface also prescribed by thermodynamics. As a result, all kinetic and thermodynamic constants represent ensemble averages over all equilibrated species, as derived in detail in Section 3.3. The formation of individual isomers via dimerization is, therefore, neither set by any kinetic hurdles nor indicative of any specific dimerization pathways or C-C bond formation TS structures. Such isomers solely reflect their thermodynamic properties as gaseous species.

The pool of alkoxides formed from reactant or product alkenes and the combined product molecules containing a given number of $\mathrm{C}$-atoms can be rigorously treated as single lumped chemical species in all kinetic and thermodynamic treatments of reactivity or selectivity. $\beta$ Scission also occurs and leads to products of intermediate chain lengths, which can subsequently 
react with the reactant alkenes to form chains differing in size from dimers or trimers. The relative contribution of these reactions is discussed in Section 3.3.

\subsection{Effects of Brønsted acid site density on propene dimerization turnover rates}

Previous studies have shown that turnover rates $\left(\mathrm{per}^{+}\right)$for hexane cracking on MFI [57], monomolecular isobutane cracking and dehydrogenation on FAU [26] and methanol dehydration on MFI or FAU [11] do not vary with Al content. Theoretical treatments confirm that isolated $\mathrm{Al}$ sites are similar in acid strength among all T-sites within a given framework and in all zeolite frameworks [12]. Here, we address the effects of Al content and of the concomitant changes in proton density $\left(\mathrm{H}^{+} /\right.$u.c., per unit cell) on dimerization turnover rates on TON, MFI and BEA. Turnover rates on TON samples with 25,39 , and $49 \mathrm{Si} / \mathrm{Al}$ ratios were the same within experimental uncertainty $\left((1.74-1.76) \times 10^{-2} \mathrm{~mol}\left(\mathrm{H}^{+}-\mathrm{s}\right)^{-1}\right.$ at $58 \mathrm{kPa}$; Fig. 4). Thus, the strength of the acid sites in TON did not vary with Al content. TON is a one-dimensional 10-MR zeolite $(0.46 \mathrm{~nm} \times 0.57 \mathrm{~nm}$ [51]; $0.57 \mathrm{~nm}$ pore-limiting diameter [58]; Fig. 5) with four crystallographically distinct T-sites (three are accessible to molecules from the connecting channels). In TON, the confining environments around each of its three accessible T-sites are similar; thus differences in the $\mathrm{Al}$ distribution with $\mathrm{Si} / \mathrm{Al}$ ratio would not have significantly influenced reactivity. The proton density can also influence reactivity when diffusional restrictions create intracrystalline gradients of alkene reactants, because such gradients would become more severe at higher proton concentrations as a result of higher reactant depletion rates. Consequently, the similar turnover rates on TON samples with $25-49 \mathrm{Si} / \mathrm{Al}$ ratios demonstrate the absence of diffusional corruptions of measured rates. These conclusions are confirmed by estimates using the Weisz-Prater criteria [59] and effectiveness factors [60] for propene reactants 
at $503 \mathrm{~K}$ on TON and MFI (Tables S2 and S3; SI) using TEM estimates of their respective crystal size [52] and reported diffusivities [61,62].

Figure 4. Propene dimerization rates (per $\mathrm{H}+)$ as a function $\mathrm{H}^{+}$per unit cell on TON $(\diamond ; 58$ $\mathrm{kPa}), \operatorname{BEA}(\mathbf{\Lambda} ; 80 \mathrm{kPa})$ and $\mathrm{MFI}(\boldsymbol{\bullet} ; 5 \mathrm{kPa})[503 \mathrm{~K} ;<5 \%$ propene conversion].

Propene dimerization turnover rates on MFI zeolites were also independent of $\mathrm{Si} / \mathrm{Al}$ ratios (14-173) and proton densities (0.4-4.5 $\mathrm{H}^{+} /$u.c.) (Fig. $4 ;<5 \%$ conversion). MFI structures contain 12 crystallographically distinct T-sites residing within three types of confining environments: (i) 10-MR straight channels ( $0.53 \times 0.56 \mathrm{~nm}$ [51]); (ii) 10-MR sinusoidal channels (0.51 x $0.55 \mathrm{~nm}$ [51]); and (iii) cage-like voids created by channel intersections $(0.70 \mathrm{~nm}$ [58]) (Fig. 5). The strength and location of the acid sites in these MFI samples must therefore be similar and measured rates must reflect intracrystalline propene concentrations in equilibrium with the extracrystalline fluid, thus leading to measured rates that are not influenced by diffusional effects. The similar turnover rates on MFI and BEA (12-MR; 3-D; $0.66 \mathrm{~nm} \times 0.67 \mathrm{~nm}$ [51]; $0.67 \mathrm{~nm}$ pore-limiting diameter and $0.69 \mathrm{~nm}$ largest cavity diameter [58]; Fig. 5) suggest that relevant transition states and intermediates are stabilized by van der Waals interactions within voids of similar size in these two frameworks, indicative of MFI protons residing at cagelike intersection environments. A similar conclusion is evident from turnover rates that are about four-fold lower on MFI than in TON, suggesting that the TON channels, similar in size to those in the MFI channels, preferentially stabilize the TS over the alkoxide precursors. Consequently, the preferential or Al-dependent location of protons within the channels of MFI would lead to turnover rates higher than on BEA and closer to those measured on TON, in contrast with measurements (Fig. 4). We conclude that $\mathrm{Al}$ atoms and the associated protons are located at 
channel intersection in these MFI samples. Methanol dehydration rates on MFI with Si/Al ratios larger than $\sim 15$ also indicate that protons reside solely at channel intersections [11].

Figure 5. Pore geometry of (a) TON down the [001] 1-D 10-MR channel, (b) MFI down the [010] 10-MR straight channel and its intersection with the 10-MR sinusoidal channel shown by the dark circle and (c) BEA down the [100] 12-MR straight channel [51]. The size of the intersections (dark circles) in MFI and BEA are given by the largest cavity diameters [58].

\subsection{Theoretical assessment of alkene oligomerization elementary steps on TON}

The elementary steps proposed in Scheme 1 bring together evidence from the effects of pressure on dimerization rates, the saturated alkoxide coverages detected in the infrared spectra, and DFT treatments that support the involvement and kinetic relevance of specific elementary steps, intermediates, and transition states. Scheme 1 illustrates the proposed sequence of elementary steps for propene reactants, but similar conclusions apply to isobutene reactions (Section 3.5) and for reactions of other alkenes and their mixtures, as we describe in a later report.

The quasi-equilibrated formation of propoxides occurs via protonation (Scheme 1, Step 1) that lead to equilibrated mixtures of primary $\left(\mathrm{C}_{3,1}{ }^{(*)}\right)$ and secondary $\left(\mathrm{C}_{3,2}{ }^{(*)}\right)$ propoxides, differing in the $\mathrm{C}$-atom that is bound to the framework; their equilibration reflects fast intramolecular hydride shifts and adsorption-desorption steps [52,63]. The preferential formation of propoxides over $\pi$-bonded propene molecules is consistent with DFT-derived free energies and with calculated vibrational frequencies (Table S1; SI) that correspond to the infrared bands detected (and to the disappearance of O-H bands) in the infrared spectra of MFI samples during propene reactions $(503 \mathrm{~K}, 10 \mathrm{kPa}$; Fig. 3). The equilibrated nature of propoxide isomers precludes any possible kinetic evidence for their relative coverages on saturated surfaces because all kinetic consequences reflect only their lumped surface concentrations. DFT-calculated structures of primary and secondary propoxides on TON (Fig. 6) have similar free energies of 
formation $\left(\Delta \mathrm{G}_{3 \mathrm{j}}\right.$ at $503 \mathrm{~K}$ and $1 \mathrm{bar}=-21.8 \mathrm{~kJ} \mathrm{~mol}^{-1}$ and $-23.2 \mathrm{~kJ} \mathrm{~mol}^{-1}$, respectively), indicating that they co-exist at comparable coverages; their negative formation free energies show that unoccupied protons are present only in trace concentrations at typical propene pressures (10-500 $\mathrm{kPa})$.
1. $\mathrm{C}_{3} \mathrm{H}_{6}{ }^{(\mathrm{g})}+\mathrm{H}^{+} \mathrm{A}^{-}$
$\theta \quad \mathrm{C}_{3} \mathrm{H}_{7}{ }^{(*)}-\mathrm{A}$
2. $\mathrm{C}_{3} \mathrm{H}_{7}{ }^{(*)}-\mathrm{A}+\mathrm{C}_{3} \mathrm{H}_{6}{ }^{(\mathrm{g})}$
$\longrightarrow \mathrm{C}_{6} \mathrm{H}_{13}{ }^{(*)}-\mathrm{A}$
3. $\quad \mathrm{C}_{6} \mathrm{H}_{13}{ }^{(*)}-\mathrm{A}$
$\Leftrightarrow \quad \mathrm{j}-\mathrm{C}_{6} \mathrm{H}_{13}{ }^{(*)}-\mathrm{A}$
4. $\quad \mathrm{C}_{6} \mathrm{H}_{13}{ }^{(*)}-\mathrm{A}$
$\Leftrightarrow \quad \mathrm{C}_{6} \mathrm{H}_{12}{ }^{(\mathrm{g})}+\mathrm{H}^{+} \mathrm{A}^{-}$

Scheme 1. Sequence of elementary steps for dimerization of propene on Brønsted acid sites $\left(\mathrm{H}^{+} \mathrm{A}^{-}\right)$where $(\mathrm{g})$ and $(*)$ indicates a gas-phase or surface bound species, respectively and $j$ indicates a particular hexene isomer. Ovals over double arrows denote quasi-equilibrated steps.

Figure 6. DFT-derived structures of the precursors for $\mathrm{C}-\mathrm{C}$ bond formation: bound propoxides with two binding configurations (a) primary $\left(\mathrm{C}_{3,1}{ }^{(*)}\right)$ and (b) secondary $\left(\mathrm{C}_{3,2}{ }^{\left({ }^{*}\right)}\right.$ ) on TON (Al3-O4; $\mathrm{RPBE}+\mathrm{D} 3 \mathrm{BJ})$ using the nomenclature defined in Scheme 2.

Scheme 2. Schematic reaction coordinate diagram for propene dimerization on Brønsted acid sites $\left(\mathrm{H}^{+} \mathrm{A}^{-}\right)$where the caps indicate the confining voids in zeolites. $\Delta G_{3, \mathrm{j}}^{\sharp}$ represents the measured free energy barriers for $\mathrm{C}-\mathrm{C}$ bond formation from respective alkoxides $G_{3, \mathrm{j}}^{*}$, where * and $\$$ indicate bound or transition states, respectively and $j$ indicates distinct attachment points.

The sole irreversible step in Scheme 1 forms a C-C bond via reactions between a reactant-derived bound alkoxide and a gaseous alkene, in a step mediated by carbenium-ion transition states (Scheme 1, Step 2). The hexenes formed can isomerize (Scheme 1, Step 3) and then desorb (Scheme 1, Step 4) or desorb and then readsorb and isomerize; these two possibilities are indistinguishable because adsorption-desorption steps are fast, as shown by the thermodynamic equilibrium among all gaseous hexene isomers formed from propene reactants [52]. The pool of hexoxide isomers, equilibrated via fast adsorption-desorption events, can also react with another alkene to form $\mathrm{C}_{9}$ chains. 
The rate of dimerization of an alkene reactant with $i$ carbon atoms via the elementary steps shown in Scheme 1 is given by:

$$
r_{i}=\frac{\sum_{j} k_{i j} K_{i j}\left[C_{i}\right]^{2}}{1+\sum_{j} K_{i j}\left[C_{i}\right]+\sum_{n}\left\langle K_{n}\right\rangle\left[C_{n}\right]}
$$

where $j$ denotes the distinct attachment point of each alkoxide isomer derived from the reactant alkene. In Equation 2, $n$ is the number of C-atoms, $C_{n}$ is the molar concentration of the products formed, and $\left\langle K_{n}>\right.$ is their equilibrium constant for alkoxide formation, ensemble-averaged over all alkoxide surface attachment points.

At conditions that lead to bound alkoxides at saturation coverages, low conversions and high reactant to product molar ratios $\left(\left[\mathrm{C}_{\mathrm{i}}\right] / \sum\left[\mathrm{C}_{\mathrm{n}}\right]>50\right.$ at fractional conversions $\left.<0.05\right)$, Equation 2 becomes:

$$
r_{i}=\frac{\sum_{j} k_{i j} K_{i j}\left[C_{i}\right]}{\sum_{j} K_{i j}}
$$

The kinetic and equilibrium parameters in Equation 3 are given by:

$$
K_{i j}=e^{\left(\frac{-\Delta G_{i j}}{R T}\right)}
$$




$$
k_{i j}=e^{\left(\frac{-\Delta G_{i j}^{\ddagger}}{R T}\right)}
$$

in terms of $\Delta \mathrm{G}_{\mathrm{ij}}{ }^{\dagger}$ and $\Delta \mathrm{G}_{\mathrm{ijj}}$ :

$$
\begin{gathered}
\Delta G_{i j}^{\ddagger}=G_{i j}^{\ddagger}-G_{i j}^{*}-G_{i}^{g} \\
\Delta G_{i j}=G_{i j}^{*}-G_{i}^{g}
\end{gathered}
$$

where the $f, *$, and $g$ notation stand for the transition state, the bound alkoxides, and the gaseous alkenes, respectively. The equilibration among all bound alkoxides, a consequence of fast hydride shifts and of their equilibration with gaseous alkene reactants and the choice of the jth configuration as a reference leads to:

$$
r_{i}=\frac{\sum_{j} k_{i j}\left(\frac{K_{i j}}{K_{i, r e f}}\right)\left[C_{i}\right]}{\sum_{j}\left(\frac{K_{i j}}{K_{i, r e f}}\right)}
$$

which, upon substitution of Equations 4-7 gives: 


$$
r_{i}=\frac{\sum_{j} e^{\frac{-\left(G_{i j}^{\neq}-G_{i}^{g}\right)}{R T}\left[C_{i}\right]}}{\sum e^{\frac{-G_{i j}^{*}}{R T}}}
$$

The definition of $\left\langle\mathrm{G}_{\mathrm{i}}{ }^{*}\right\rangle$ and $\left\langle\mathrm{G}_{\mathrm{i}}{ }^{\left({ }^{*}\right)}\right\rangle$ as the exponential averages of the TS and alkoxide free energies over all bound alkoxide configurations then gives:

$$
\begin{aligned}
& e^{\frac{-\left\langle G_{i}^{\neq}\right\rangle}{R T}}=\sum_{j} e^{\frac{-G_{i j}^{\neq}}{R T}} \\
& e^{\frac{-\left\langle\Delta G_{i}^{*}\right\rangle}{R T}}=\sum_{j} e^{\frac{-\Delta G_{i j}^{*}}{R T}}
\end{aligned}
$$

These definitions then allow the dimerization rate of an alkene with i carbon atoms (Equation 9) proceeding through all configurations of bound alkoxides to be expressed as:

$$
\begin{aligned}
& -\left(\left\langle G_{i}^{\neq}\right\rangle-\left\langle G_{i}^{*}\right\rangle-G_{i}^{g}\right) \\
& r_{i}=e \quad R T \quad\left[C_{i}\right]=k_{i}\left[C_{i}\right]
\end{aligned}
$$

This rate equation accounts for all $\mathrm{C}-\mathrm{C}$ bond formation $\mathrm{TS}$ structures, irrespective of the equilibrated alkoxide from which they formed, and for all bound alkoxides, irrespective of which TS they lead to in their conversion to products. This equation, however, does not account for the 
transition states that form all of the product isomers. Instead, we surmise, as is customary in transition state formalisms, that the exponential consequences of small differences in free energies among these TS structures for reactivity (Eq. 5) will cause one dimer structure to form preferentially, with the others formed via rapid hydride and methyl shifts upon readsorption. The resulting equation (Eq. 12) and the ensemble-averaging formalism that led to i reflect a kinetic treatment that is general to all catalysts and alkenes with kinetically-relevant reactions involving bound species in quasi-equilibrium with their gaseous precursors and present at saturation coverages.

DFT-derived free energies of reactants, intermediates, transition states and products on TON (Fig. 7) are consistent with the assumptions required to obtain the functional form of the rate equation shown as Equation 12. The formation of $\mathrm{C}-\mathrm{C}$ bonds via reactions of propene with secondary $\left(\mathrm{G}_{3,2^{\ddagger}}\right)$ and primary $\left(\mathrm{G}_{3,1^{\ddagger}}\right)$ propoxides results in hexene isomers with $2 \mathrm{MP}$ and $\mathrm{nH}$ backbone, respectively (reactant, product and TS structures in Table 2). The TS free energies indicate that $\mathrm{C}-\mathrm{C}$ bonds form predominantly from the secondary propoxide, which gives free energy values smaller $\left(\mathrm{G}_{3,2}{ }^{\sharp}=103 \mathrm{~kJ} \mathrm{~mol}^{-1}\right.$; referenced to bare surface and gaseous reactants) than its equilibrated primary analog $\left(\mathrm{G}_{3,1}{ }^{\sharp}=136 \mathrm{~kJ} \mathrm{~mol}^{-1}\right)$ for the formation of their respective favored isomer. The total rate of dimer formation, however, is dependent on the reaction of a propene with each alkoxide (primary or secondary) because each precursor needs a path through which it is consumed. The relative contributions of each path cannot be experimentally discerned because the initial alkoxide products rapidly isomerize and lead to a hexene dimer pool prescribed by thermodynamic instead of kinetic preferences.

Figure 7. DFT-derived reaction free energy diagrams of propene dimerization on H-TON (RPBE+D3BJ; $503 \mathrm{~K}, 1$ bar) where i,j ${ }^{\ddagger}$ represent transition states for either alkoxide and C-C bond formation with $i$ carbons and attachment $j \cdot \mathrm{G}_{\mathrm{i}}{ }^{(\mathrm{g})}$ and $\mathrm{G}_{\mathrm{i}, \mathrm{j}}{ }^{(*)}$ represent alkenes with $i$ carbons 
in gaseous and alkoxide state, respectively. Energies are relative to a bare surface and gaseous reactants. 
Table 2. DFT-derived structures of reactants, transition states and products involved in the C-C bond formation elementary steps from a primary propoxide and secondary propoxide on TON (RPBE+D3BJ).

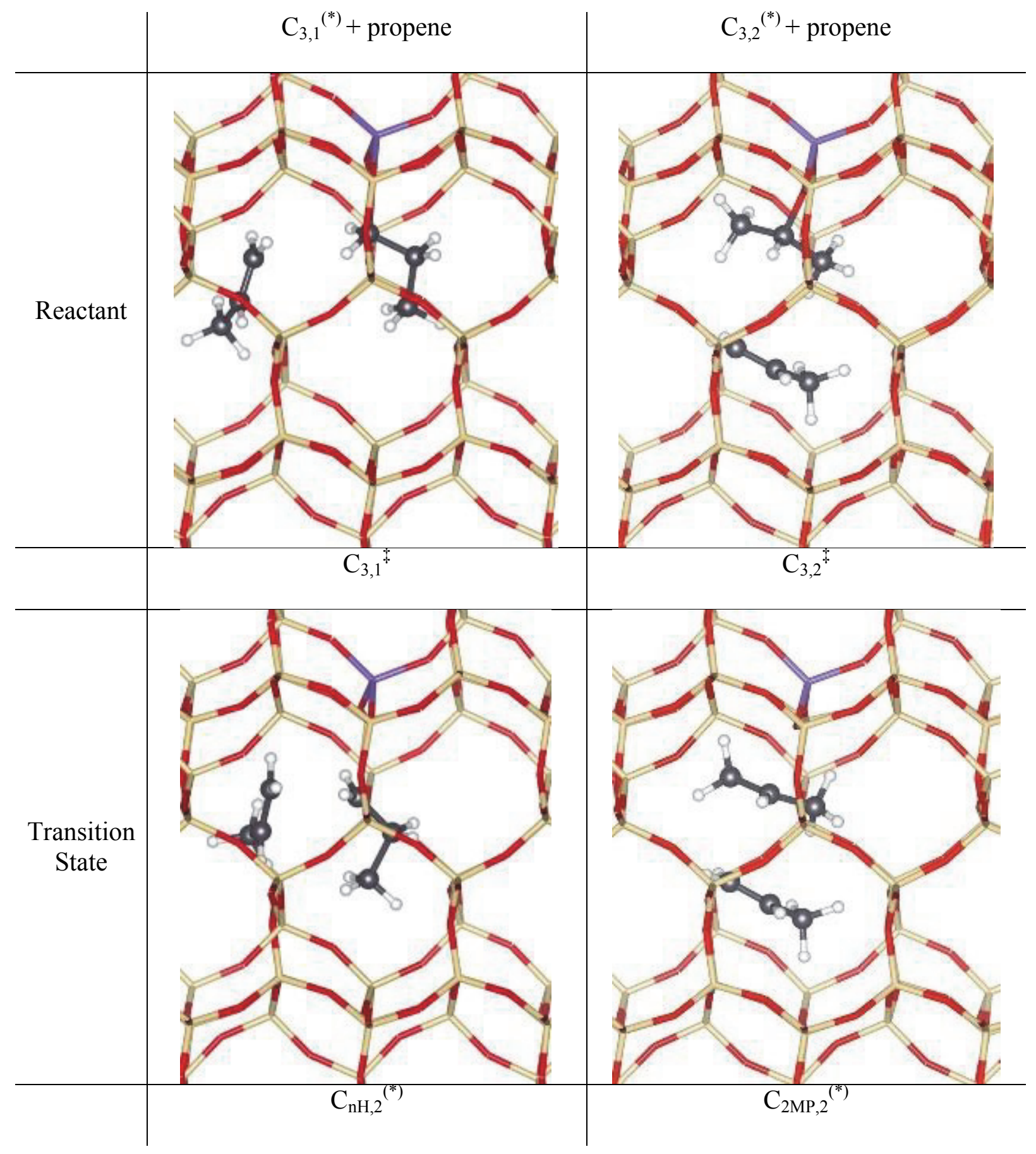




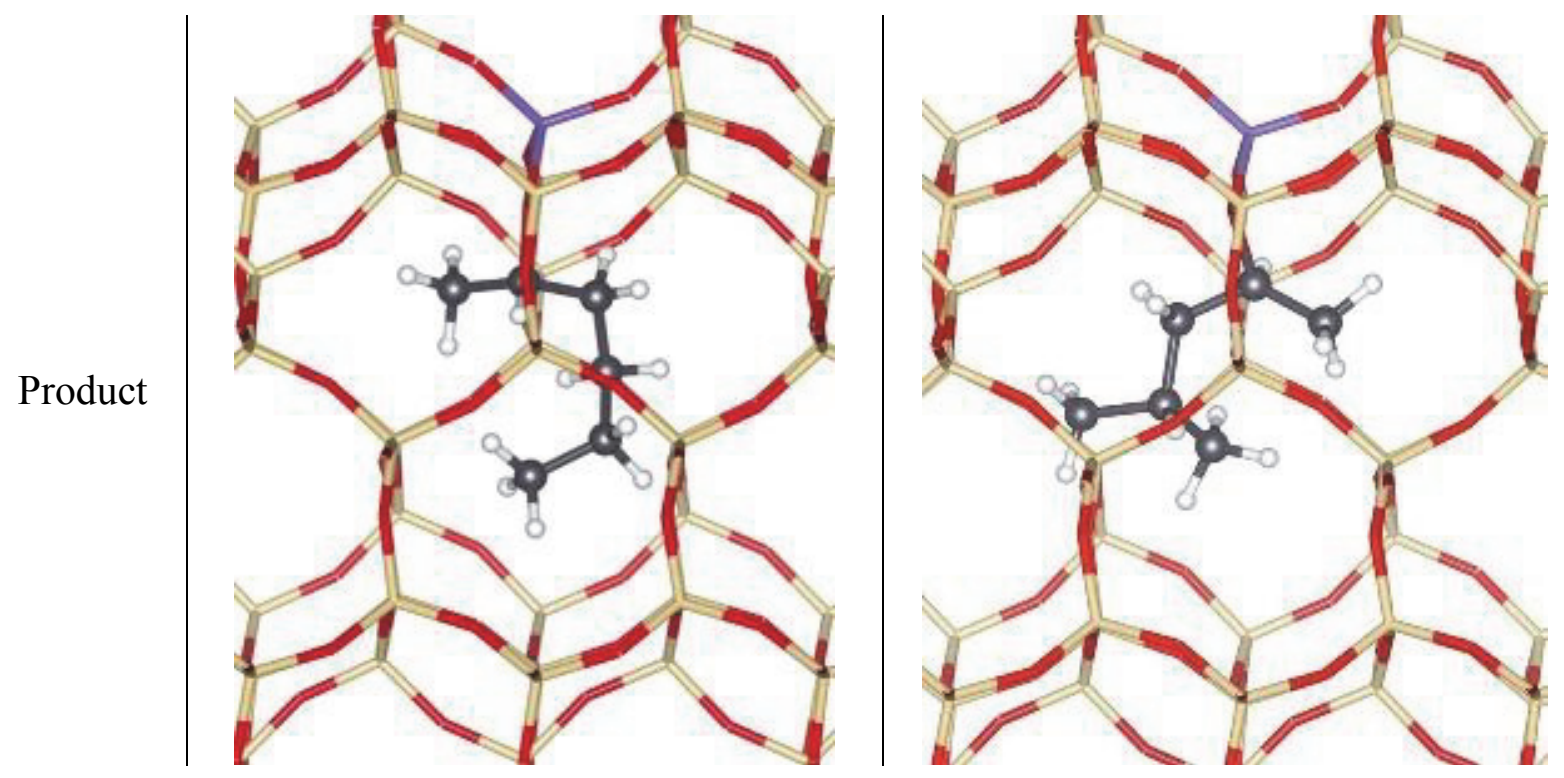

\subsection{Consequences of confinement for alkene dimerization turnover rates}

Propene dimerization turnover rates show a similar linear dependence on pressure on all solid acids, but the first-order rate constants vary significantly among different framework structures, even for aluminosilicates that contain acid sites of similar strength (Fig. 2). These measured rate constants $\left(k_{3}\right.$; Eq. 12) reflect the energy of the ion-pair TS that mediates $\mathrm{C}-\mathrm{C}$ bond formation relative to that of a smaller propoxide, present in an equilibrated mixture of binding configurations, and a gaseous propene; they decreased monotonically as the size of the aluminosilicate voids increased (Fig. 8). Void sizes, in the context of Figure 7, are defined using strictly geometric features and more specifically by describing size in terms of the largest sphere that can be fully inscribed within each framework [58]. The size of MFI voids is taken here as that of its channel intersections, because Al atoms appear to reside predominantly at such locations at these $\mathrm{Si} / \mathrm{Al}$ ratios $[64,65]$; moreover, turnover rates on MFI are similar to those for protons in BEA voids that resemble such intersections in size (Table 4). 
The C-C bond formation TS on TON is significantly larger than either of the two propoxide isomers when such volumes are calculated using van der Waals radii for $\mathrm{C}$ and $\mathrm{H}$ $\left(0.12 \mathrm{~nm}^{3}\right.$ vs. 0.055 or $\left.0.052 \mathrm{~nm}^{3}\right)$. Their diameters, defined here as that of the sphere of equivalent volume $\left\langle d_{v d W^{>}}>\right.$, are $0.61 \mathrm{~nm}$ and $0.46-0.47 \mathrm{~nm}$ for the TS and the two propoxides, respectively. These size differences, and the accompanying changes in the external surface areas of these chemical species (Table 3), allow more effective van der Waals contacts with the framework for TS structures than for bound propoxides. As a result, TS structures benefit from confinement more strongly than bound alkoxides, leading to reactivity enhancements as voids approach the size of the TS structures (Fig. 8). These TS and alkoxide dimensions, reported here from DFT-derived structures in TON vary only slightly among different frameworks. For example, the volume and $\left\langle d_{v d W}\right\rangle$ of the optimized TS structure on HPW, without any confinement, is $0.11 \mathrm{~nm}^{3}$ and $0.60 \mathrm{~nm}$, respectively. These geometric descriptors of size for the organic moieties are similar among diverse acids, but represent qualitative descriptor of the "fit" or organic moieties within inorganic voids. The calculated $\left\langle d_{v d W}>\right.$ value for the TS that forms the dimer with the $2 \mathrm{MP}$ backbone from s-propoxide $\left(3,2^{+}\right)$on TON $(0.61 \mathrm{~nm})$ is larger than the largest inscribed sphere in TON voids $(0.57 \mathrm{~nm})$, an indication of the incompleteness of spherical constructs to describe the less regular shapes of the TS, the alkoxides, and the void structures.

These geometric descriptors seek to account for the "fit" between the cavity and the organic moieties in a way that captures their van der Waals contacts. More complete and rigorous descriptions must replace such heuristic visualizations of the pore space and its contents in terms of geometric constructs with van der Waals interaction energies derived from DFT functionals $[28,29]$ that properly describe them. Such strategies would allow accurate assessments of "fit" for TS and alkoxide structures, diverse in size and shape among alkene 
reactants, within voids, also diverse in size and shape among microporous and mesoporous frameworks. In doing so, such void and molecular geometries aim to describe the consequences of confinement in the proper energy context, in terms of enthalpies and free energies (Eqs. 5 and 12).

DFT functionals that rigorously describe the van der Waals interactions among atoms allow the dispersive contributions to be extracted from DFT-derived total energies. These estimates include the dispersive interactions among all atoms, including those within the framework and the organic moieties. The latter are subtracted here from the total dispersive component to isolate the van der Waals interactions between the atoms in the organic moiety and those in the framework. These interactions between the organic moiety (alkoxide or transition state) and the void walls are given by:

$$
\begin{aligned}
& E_{v d W}^{(*)}=E_{i j}^{(*)}-E_{\mathrm{HZ}}-E_{i}^{(g)} \\
& E_{v d W}{ }^{\ddagger}=E_{i j}^{\ddagger}-E_{\mathrm{HZ}}-2 E_{i}^{(g)} \\
& E_{v d W}=E_{i j}^{\ddagger}-E_{i j}^{(*)}-E_{i}^{(g)}
\end{aligned}
$$

The energies in these equations represent the dispersive component of the electronic energies for the alkoxide $\left(E_{i j}^{(*)}\right)$, the transition state $\left(E_{i j}^{\ddagger}\right)$, the proton form of the solid acid $\left(E_{\mathrm{HZ}}\right)$ and the gaseous species $\left(E_{i}^{(g)}\right)$; the remaining component of the total energy for each structure represents the quantum mechanical energy. These dispersive interaction energies are about $100 \mathrm{~kJ} \mathrm{~mol}^{-1}$ stronger for the propene dimerization transition state $\left(E_{v d W^{\ddagger}}{ }^{\ddagger}=-226 \mathrm{~kJ} \mathrm{~mol}^{-1}\right)$ than either alkoxide precursor or their ensemble average $\left(E_{i}^{(*)}=-118 \mathrm{~kJ} \mathrm{~mol}^{-1}\right)$ (Eq. 12; Table 3) on TON, consistent with the preferential stabilization of the transition state, which accounts for the observed effects of confinement (Fig. 8). 
The strength of these dispersive interactions depends on the confining voids and such effects differ for the transition states and alkoxide precursors. We probe these effects here by calculating the dispersive interactions for different frameworks using the DFT-derived transition state structure (addition of propene to s-propoxide to form 2MP skeletal isomer; $3,2^{\star}$ ) optimized at the T-3 site of TON onto the T-12 site in MFI, which is located in the intersection, or the unique T-site in FAU, which is located in the supercage (methods described in Section 2.4). This approach, in its current context and implementation, does not sample or ensemble-average over all T-sites in each framework; it also does not account for the slight differences in TS shape, when their structure is separately converged on different frameworks. The s-propoxide is used here as the reference because dispersive interactions are similar of alkoxides that differ only in their surface attachment point (shown for propoxides in TON; Table 3).

The dispersive component of the propene dimerization energy barrier $\left(E_{v d W} ;\right.$ Eq. 15) becomes less negative as the voids become larger in TON, MFI and FAU zeolites (Fig. 9), consistent with less effective van der Waals contacts and smaller rate constants. The trends in Figure 9 between DFT-derived $E_{v d W}$ and measured dimerization rate constants indicate that such energies represent an accurate descriptor of reactivity, even though they do not account for (i) any changes in TS structures among frameworks; (ii) the potential distortion of the framework in response to the presence of the TS; and (iii) the ensemble-averaging reflected in the measured rates, but not in these $E_{v d W}{ }^{\ddagger}$ estimates.

Figure 8. First-order rate constants ( $k_{3}$, per proton) for propene dimerization as a function of void diameter, defined as the largest sphere that can be inscribed within each framework type [503 K; $<5 \%$ propene conversion; dashed curve indicates a trend]. 
Table 3. DFT-derived van der Waals volumes, surface areas, diameters and dispersive energies of the two propoxide precursors and the $\mathrm{C}-\mathrm{C}$ bond formation transition state structures from propene dimerization on H-TON. The diameters are calculated assuming a sphere of equivalent volume.

\begin{tabular}{|c|c|c|c|c|}
\hline Structure in TON & $\mathrm{V}_{\mathrm{vdW}}\left[\mathrm{nm}^{3}\right]$ & $\mathrm{SA}_{\mathrm{vdW}}\left[\mathrm{nm}^{2}\right]$ & $\mathrm{d}_{\mathrm{vdW}}[\mathrm{nm}]$ & $\begin{array}{c}E_{v d W}^{(*)} \text { or } E_{v d W}{ }^{\ddagger} \\
{\left[\mathrm{kJ} \mathrm{mol}^{-1}\right]}\end{array}$ \\
\hline p-propoxide $\left(3,1^{*}\right)$ & 0.052 & 0.82 & 0.46 & -117 \\
\hline s-propoxide $\left(3,2^{*}\right)$ & 0.055 & 0.82 & 0.47 & -120 \\
\hline C-C $\left(3,2^{\ddagger}\right)$ & 0.12 & 1.4 & 0.61 & -226 \\
\hline
\end{tabular}

Table 4. First-order rate constants for propene dimerization $\left(k_{\text {eff }}\right)$ as a function of void diameter, as determined by modeling the void environment with cylinders and spheres of varying sizes for TON $(\mathrm{Si} / \mathrm{Al}=40), \mathrm{MFI}(\mathrm{Si} / \mathrm{Al}=40)$ and $\mathrm{BEA}(\mathrm{Si} / \mathrm{Al}=12.5)$ [503 $\mathrm{K} ;<5 \%$ propene conversion].

\begin{tabular}{|c|c|c|c|}
\hline Zeolite & $\begin{array}{c}\mathrm{k}_{\text {eff,3 }} \\
{\left[\mu \mathrm{mol}\left(\mathrm{H}^{+}-\mathrm{s}-\mathrm{kPa}\right)^{-1}\right]}\end{array}$ & Void Environment & Void Diameter [nm] \\
\hline TON & $300 \pm 20$ & Channel & 0.57 \\
\hline \multirow{2}{*}{ MFI } & \multirow{2}{*}{$56 \pm 4$} & Channel & 0.50 \\
\cline { 3 - 4 } & & Intersection & 0.70 \\
\hline BEA & $61 \pm 2$ & Channel & 0.69 \\
\hline FAU & $22 \pm 2$ & Supercage & 1.19 \\
\hline
\end{tabular}

Figure 9. First-order rate constants ( $k_{i}$, per proton; $\left.503 \mathrm{~K}\right)$ for propene dimerization as a function of $\mathrm{E}_{\mathrm{vdw}}(\mathrm{D} 3 \mathrm{BJ})$ defined in Equation 15.

The use of $E_{v d W}$ values represents a conceptual shift from purely geometric arguments into the realm of the energies of the dispersive interactions that confer reactivity benefits through confinement effects. Its completeness as a descriptor requires that it be able to bridge the properties of the size and shape of the confining voids and of the confined organic moieties, which we demonstrate next by examining isobutene dimerization reactivity on TON frameworks. Isobutene dimerization turnover rates are proportional to isobutene pressure on TON (Fig. 10) and the absence of unperturbed or broad perturbed $\mathrm{O}-\mathrm{H}$ bands in the infrared spectra during reaction show that acid sites are saturated with isobutene-derived alkoxides $(8 \mathrm{kPa}$ isobutene; Fig. 3 right, Spectra c; $503 \mathrm{~K}$ ). These spectra do not show broad bands near $2800 \mathrm{~cm}^{-1}$, the 
frequency range expected from theoretical treatments for $\pi$-bonded alkenes at protons (SI Table S1 and [20]). DFT-derived Gibbs free energies of formation on TON indicate that alkoxides with surface attachments at the primary $\mathrm{C}$-atom $\left(\mathrm{C}_{4,1}{ }^{(*)}\right)$ are slightly more stable than those bound at their tertiary C-atoms $\left(\mathrm{C}_{4,3}{ }^{(*)}\right)\left(\Delta \mathrm{G}_{4}\right.$

$$
{ }_{, 1}=-24.8 \mathrm{~kJ} \mathrm{~mol}^{-1} ; \Delta \mathrm{G}_{4,3}-8.23 \mathrm{~kJ} \mathrm{~mol}^{-1} ; 503 \mathrm{~K} ; 1 \text { bar), but similar in stability to } \pi \text {-bonded }
$$

isobutene $\left(\Delta \mathrm{G}_{4, \pi}=-24.2 \mathrm{~kJ} \mathrm{~mol}^{-1}\right)$. C-C bond formation, however, occurs with the lowest barrier from the tertiary isobutoxide to form the 2,2,4-trimethylpentene backbone than for from the primary isobutoxide to the 2,5 -dimethylhexene backbone $\left(\Delta \Delta \mathrm{G}^{t}=33 \mathrm{~kJ} \mathrm{~mol}^{-1} ; 503 \mathrm{~K} ; 1\right.$ bar).

The measured isobutene dimerization rate constants $\left(\right.$ per $\left.\mathrm{H}^{+}\right)$on TON are about five-fold larger than for propene on TON $\left(0.30 \pm 0.02\right.$ vs. $\left.1.6 \pm 0.1 \mathrm{mmol}(\mathrm{H}+-\mathrm{s}-\mathrm{kPa})^{-1}\right)$. Such reactivity differences, for a given confining framework, reflect, in part, the more effective van der Waals contacts between this larger TS and the confining framework, where $E_{v d W}{ }^{\ddagger}=-327 \mathrm{~kJ} \mathrm{~mol}^{-1}$ for isobutene dimerization versus $-226 \mathrm{~kJ} \mathrm{~mol}^{-1}$ for propene dimerization (Tables 3,5 ; structures for isobutene and propene TS structures in Fig. 11). Such differences in reactivity also reflect the higher proton affinity of the larger and more substituted TS structure that mediates C-C bond formation from isobutene reactants. These additive effects of TS size on proton affinity and van der Waals stabilization must be separated for predictions of the specific effects on confinement on reactivity. This requires, in turn, that the effects of TS size on proton affinity be determined using solid acids with protons within mesoporous voids, as we intend to address in a later report.

The oxygen atoms that stabilize the void contents via van der Waals interactions move in response to the presence of intracrystalline organic moieties through local distortions of the framework O-T-O bonds. In doing so, these distortions favor more effective van der Waals contacts, but also lead to compensating energy losses associated with the framework distortions, 
which are reflected in the quantum mechanical component of the functional used to evaluate the TS and alkoxide energies. The stronger dispersive interactions for isobutene than propene dimerization TS structures are conferred, in part, by a greater distortion of the inorganic framework. Such compensating factors, and in fact the theoretical detection of such framework distortion, become evident only when DFT methods include functionals rigorously account for dispersive interactions.

Here, we describe the magnitude of these lattice distortions from the displacement of each framework atom from its location in TON in the proton form and in the optimized structure containing the TS. The TON void structure led us to define a cylindrical coordinate system with the origin at the center of the 10-MR channel and with each lattice oxygen atom $m$ that creates the inner shell of the 10-MR channel having $\left(\mathrm{R}_{\mathrm{ij}}^{\dagger}, \theta_{\mathrm{ij}}^{\ddagger}, \mathrm{z}_{\mathrm{ij}}^{\dagger}\right)_{\mathrm{m}}$ and $\left(\mathrm{R}_{\mathrm{H}}, \theta_{\mathrm{H}}, \mathrm{z}_{\mathrm{H}}\right)_{\mathrm{m}}$ coordinates for the framework with the TS and the proton, respectively (Scheme 3). The mean framework distortion with respect to the proton form is then defined by averaging the value of:

$$
\left\langle R_{i j}^{\neq}\right\rangle=\frac{\sum_{m}\left(R_{i j}\right)_{m}}{\sum_{m} m}
$$

$\Delta R_{i j}=\left\langle R_{H}\right\rangle-\left\langle R_{i j}^{\ddagger}\right\rangle$

This mean distortion is $0.34 \mathrm{pm}$ for the isobutene dimerization TS, but much smaller $(0.055 \mathrm{pm})$ for the propene dimerization TS; such trends reflect how the minimum energy for the TSframework system is achieved by the more effective van der Waals contacts that can be achieved by distortion as the TS structures approach the size of the confining voids. The energetic penalty of such distortion partially offsets the stronger dispersive stabilization of the isobutene TS compared with that for propene dimerization. These energetic penalties are not considered in 
developing the $\mathrm{E}_{\mathrm{vdW}}$ metric used to describe the reactivity of TON, MFI and FAU in Figure 9, but the small distortions $(\Delta \mathrm{R}=0.055 \mathrm{pm})$ even in the smallest framework structure (TON) suggest that the effects of void size depend predominantly on the dispersive component of TS stabilization energies. It is evident, however, that such dispersive energy descriptors are incomplete, because the framework responds to the presence of occluded organic moieties at an energy penalty that becomes more significant as the organic and void structures become more similar in size and shape. The effects of molecular size must also be described in terms of the proton affinity of the species that become protonated at the TS, while the properties of the acid sites, specifically the stability of the conjugate anions in solid acids, must also be considered when solid acids include structures with compositions different from the aluminosilicates, as discussed in Section 3.6.

Figure 10. Alkene dimerization turnover rates as a function of propene $(\bullet)$ and isobutene $(\bullet)$ pressure on TON [503 K; $<5 \%$ propene conversion; dashed lines represent linear regression fits]. The rate constant for isobutene dimerization is 5.3 times larger than that for propene, due to a larger, more stable transition state.

Table 5. DFT-derived van der Waals volumes, surface areas, diameters and dispersive energies of the isobutene-derived precursors and the $\mathrm{C}$ - $\mathrm{C}$ bond formation transition state structures from isobutene dimerization on H-TON. The diameters are calculated assuming a sphere of equivalent volume.

\begin{tabular}{|c|c|c|c|c|}
\hline Structure in TON & $\mathrm{V}_{\mathrm{vdW}}\left[\mathrm{nm}^{3}\right]$ & $\mathrm{SA}_{\mathrm{vdW}}\left[\mathrm{nm}^{2}\right]$ & $\mathrm{d}_{\mathrm{vdW}}[\mathrm{nm}]$ & $\begin{array}{c}E_{v d W}{ }^{(*)} \text { or } \\
E_{v d W}^{*} \\
{\left[\mathrm{~kJ} \mathrm{~mol}^{-1}\right]}\end{array}$ \\
\hline$\pi$-bonded isobutene $(4, \pi)$ & 0.080 & 0.96 & 0.53 & -107 \\
\hline p-isobutoxide $\left(4,1^{*}\right)$ & 0.074 & 1.00 & 0.51 & -140 \\
\hline t-isobutoxide $\left(4,3^{*}\right)$ & 0.071 & 0.99 & 0.52 & -153 \\
\hline C-C $\left(4,3^{\ddagger}\right)$ & 0.15 & 1.7 & 0.66 & -327 \\
\hline
\end{tabular}


Figure 11. DFT-derived structures of transition states for $\mathrm{C}-\mathrm{C}$ bond formation via secondary propoxide (top) and a tertiary butoxide (bottom) on TON (RPBE+D3BJ). The van der Waals radii for organic atoms are used to illustrate its occupied volume.

Scheme 3. DFT-derived structures for H-TON (top) and transition states $C_{3,2}^{\sharp}$ and $C_{4,3}^{\sharp}$ (bottom) $(\mathrm{RPBE}+\mathrm{D} 3 \mathrm{BJ})$. An arithmetic mean of the radii of each oxygen atom $m$ that line the 1-D channel, represented by the arrows, is used to describe the distortion that occurs increase interaction with the TS.

\subsection{Consequences of acid strength on propene dimerization turnover rates}

These effects of molecular size and confinement on reactivity occur in parallel with the effects of the conjugate anion and specifically on the relative stability of the ion-pair TS structures and the bound alkene-derived precursors. The stability of the conjugate anion, and thus acid strength, depends on the energy required to remove a proton from the solid acid to noninteracting distances. This deprotonation energy (DPE) decreases with increasing acid strength. Such conjugate anions are present in fully formed ion-pairs at TS structures, but to a lesser extent in the less charged structures of adsorbed precursors, which retain significant covalency in the case of alkoxides. The C-C bond formation from a s-propoxide on TON involves a TS with equal and opposite nearly full charges at the cation and the anion moieties (+/-0.91) (Scheme 4). In contrast, the equilibrated primary and secondary alkoxide have a much smaller net charge $(+0.33-0.35$; Scheme 4), where these latter finite charges reflect the shared electrons of the covalent bond.

Scheme 4. DFT-derived charge distributions and van der Waals volumes for the two propoxide precursors and the $\mathrm{C}-\mathrm{C}$ bond formation transition state structures from propene dimerization $(\mathrm{H}-$ TON, RPBE+D3BJ). The pore network was deleted after optimization for visual clarity. $G_{3,2}^{\ddagger}$ 
represents the C-C bond formation TS from s-propoxide and $G_{3, j}^{*} \ddagger$ represents propoxides at $j$ distinct attachment points.

Isomorphous substitution of different heteroatoms $(\mathrm{Al}, \mathrm{Ga}, \mathrm{Fe}, \mathrm{B})$ into a crystalline silicate framework influences acid strength, as shown by DFT-derived DPE values from large cluster models [11], but does not significantly perturb the geometric details of the confining voids. These samples allow acid strength effects on reactivity to be probed without concomitant changes in confining effects. Propene dimerization turnover rates were proportional to propene pressure on all H-X-MFI samples (Fig. S1a; SI), but first-order rate constants were strongly influenced by the identity of the heteroatom that provides the framework charge that is balanced by the protons. These rate constants decreased exponentially with increasing DPE (Fig. 12), because the more stable conjugate anions in stronger acids stabilize TS structures more than alkoxide precursors. This preferential stabilization results from the different charges that these two structures place at the framework and thus lowers the activation barrier (Eq. 14). The similar rate constants measured on $\mathrm{Ga}$ and $\mathrm{Fe}$ that are lower in reactivity than $\mathrm{Al}$ are consistent with trends found in previous studies of methanol dehydration [11] and trend similarly with results for hexane cracking and propene/1-butene oligomerization $[13,66]$.

The more reactive nature of stronger acids is also evident on acids of diverse strength but without confining voids of molecular dimensions, such as amorphous silica alumina (SiAl) and Keggin polyoxometalate clusters, for which different central atoms change both the number of protons and the strength of the acid sites [9]. The DPE of amorphous silica alumina is taken as that of protons in H-Al-MFI, because neither framework structure or T-site location influences DPE values for aluminosilicates [12]. The DPE values for POM clusters were calculated for clusters with s-propoxides at all locations except for the proton being removed (here $\mathrm{C}_{3,2}{ }^{\left({ }^{*}\right)}$; 
Section 2.4, Fig. 1) because of the near-saturation propoxide coverages present during oligomerization reactions. The first-order rate constants again increase exponentially with decreasing DPE for SiAl and POM clusters with P and Si central atoms (Fig. 12), in agreement with the difference in calculated partial charge between the TS (+0.94; Scheme 5) and either propoxide precursor $(+0.32-0.35$; Scheme 5$)$ on HPW because the cationic C-C bond formation transition state energies are more sensitive to changes in electrostatics (reflected in DPE values) than reactive intermediates of less charge.

Scheme 5. DFT-derived charge distributions for the two propoxide precursors and the C-C bond formation transition state structures from propene dimerization (HPW, PW91). $G_{3,2}^{\ddagger}$ represents the $\mathrm{C}-\mathrm{C}$ bond formation TS from s-propoxide and $G^{*}{ }_{3, \mathrm{j}} \ddagger$ represents propoxides at $j$ distinct attachment points.

Figure 12. First-order rate constants for propene dimerization $\left(k_{3}\right)$ as a function of deprotonation energy for both unconfined and MFI-confined protons [503 K; $<5 \%$ propene conversion].

The similar effects of DPE on rate constants for unconfined and confined protons (Fig. 12) indicate that in both cases stronger acids preferentially stabilize dimerization transition states over their alkoxide precursors. This enhancement of reactivity for strong acids is general for all reactions which have TS that are more charged than their precursors $[8,9,11,27]$. The slopes ($d(\ln (k 3)) / d(D P E))$ in Figure 11 are similar and much smaller than unity on MFI $(0.06 \pm 0.02)$ and mesoporous acids $(0.05 \pm 0.01)$, which suggest that both types of solid acids recover most of the electrostatic component of deprotonation energies $[67,68]$ through the cation-anion interactions upon formation of the ion-pair transition states. This extensive recovery of the energy required to separate the proton from its conjugate anion is similar to the trends obtained from methanol dehydration on POM clusters and heterosilicates with MFI frameworks [11,69]. 
The DFT-derived enthalpy of formation of the covalently-bound alkoxides that act as bound precursors to TS structures (relative to a bare proton and gaseous propene) and their partial charges do not depend on DPE (Fig. 13), as also found for bound methoxy groups on POM clusters [9]. Consequently, only the TS term in Equation 15 depends on DPE and thus on acid strength. The offset between the two separate trend lines for MFI heterosilicates and POM clusters (Fig. 12) reflects the additive consequences of the preferential van der Waals stabilization of the TS over alkoxides for reactivity.

These mechanistic interpretations of the effects of acid strength and confinement on alkene oligomerization turnover rates and the previously unrecognized lattice distortions that increase van der Waals contacts between organic moieties and framework voids are generally applicable to the understanding of reactivity and selectivity for acid-catalyzed reactions mediated by transition states that are larger and/or more charged than their relevant precursors.

Figure 13. Calculated formation enthalpies $(503 \mathrm{~K}$ ) of secondary-propoxides on bare Keggin polyoxometalates as a function of deprotonation energy.

\section{Conclusions}

The underpinning descriptors for the effects of confinement and acid strength on the reactivity of Brønsted acids for alkene oligomerization were examined by comparing different reactants (propene and isobutene) on a variety of microporous and mesoporous solid acids. Firstorder kinetic dependences, in-situ spectroscopic evidence and theoretical examination of the mechanism reveals $\mathrm{C}-\mathrm{C}$ bond formation between bound alkoxides and gaseous alkene is kinetically limiting and occurs on surfaces saturated with alkene-derived precursors. Rate constants for propene dimerization increase with decreasing void size of aluminosilicate frameworks because the transition state formed in the voids is larger than its alkene-derived 
precursors and result in more stabilizing van der Waals interactions. These effects, combined with higher proton affinity, also result in higher dimerization rate constants for isobutene coupling on TON than for propene. The sizes of the transition states and precursors are estimated from DFT-derived volumes using van der Waals radii of all atoms and compared with reported sizes of the largest inscribed sphere for the different frameworks. These geometric arguments for confinement, however, can be replaced with DFT-calculated dispersive energies, which are more rigorous descriptors for van der Waals interactions between organic moieties and their inorganic hosts and their stabilizing effects. The first-order rate constant, for a given reaction in confining environments with different void size and shape, increases as this dispersive energy (here calculated as the difference between the TS and the alkoxide) becomes more negative, which indicates stronger interactions between the TS and the pore walls. These descriptors still remain incomplete, however, because they do not include how the framework responds to the presence of occluded organic moieties especially ones large in size, which results in local distortions of OT-O bonds to increase the van der Waals interactions, consistent with calculated distortions during isobutene versus propene dimerization.

The transition state and the bound precursors do not only differ in size, they also differ in charge, leading to effects of acid strength. Stronger acids, for a given confining environment, exhibit higher reactivity than weaker acids because their anionic conjugate bases better stabilize the positively charged carbenium ion transition state involved in $\mathrm{C}-\mathrm{C}$ bond formation as compared to the covalently-bound alkoxide precursor. These combined results demonstrate mechanistic understanding of alkene oligomerization on solid acids and the effects of acid strength and confinement to increase reactivity of alkene chain growth pathways that extends to 
other light alkenes as well as a plethora of zeolitic, mesoporous or supported polyoxometalate catalysts.

\section{Acknowledgments}

We thank Professor Matthew Neurock (University of Minnesota) and Dr. David Hibbitts (UCBerkeley, now at University of Florida) for their technical advice on theoretical matters related to this manuscript. We also acknowledge thank Dr. David Law (BP) for the Tri-cat MFI sample, Dr. Neng Guo (BP) for the synthesis of the Ga and B MFI materials, and Dr. Stacey Zones (Chevron) for the Fe-MFI sample, as well as general guidance about zeolite materials and their physicochemical properties. MLS acknowledges a Graduate Research Fellowship from the

National Science Foundation and computational resources from National Science Foundation's Extreme Science and Engineering Discovery Environment (XSEDE; ACI-1053575 (CTS140040

Liand TG-CHE140066)). The financial support for this research from BP p.l.c. as part of the $\mathrm{XC}^{2}$ Program is gratefully acknowledged.

\section{References}

[1] S.A. Tabak, F.J. Krambeck, W.E. Garwood, CONVERSION OF PROPYLENE AND BUTYLENE OVER ZSM-5 CATALYST, Aiche J. 32 (1986) 1526-1531. doi:10.1002/aic.690320913.

[2] R.J. Quann, L.A. Green, S.A. Tabak, F.J. Krambeck, CHEMISTRY OF OLEFIN OLIGOMERIZATION OVER ZSM-5 CATALYST, Ind. Eng. Chem. Res. 27 (1988) 565-570. doi:10.1021/ie00076a006.

[3] C.J. Norton, OLEFIN POLYMERIZATION OVER SYNTHETIC MOLECULAR SIEVES, Ind. Eng. Chem. Process Des. Dev. 3 (1964) 230-\&. doi:10.1021/i260011a009.

[4] O. Johnson, ACIDITY AND POLYMERIZATION ACTIVITY OF SOLID ACID CATALYSTS, J. Phys. Chem. 59 (1955) 827-831. doi:10.1021/j150531a007.

[5] A.J. Jones, S.I. Zones, E. Iglesia, Implications of Transition State Confinement within Small Voids for Acid Catalysis, J. Phys. Chem. C. 118 (2014) 17787-17800. doi:10.1021/jp5050095.

[6] R. Gounder, E. Iglesia, The catalytic diversity of zeolites: confinement and solvation effects within voids of molecular dimensions, Chem. Commun. 49 (2013) 3491-3509. doi:10.1039/C3CC40731D.

[7] A. Bhan, E. Iglesia, A link between reactivity and local structure in acid catalysis on zeolites, Acc. Chem. Res. 41 (2008) 559-567. doi:10.1021/ar700181t. 
[8] W. Knaeble, R.T. Carr, E. Iglesia, Mechanistic interpretation of the effects of acid strength on alkane isomerization turnover rates and selectivity, J. Catal. 319 (2014) 283-296. doi:http://dx.doi.org/10.1016/j.jcat.2014.09.005.

[9] R.T. Carr, M. Neurock, E. Iglesia, Catalytic consequences of acid strength in the conversion of methanol to dimethyl ether, J. Catal. 278 (2011) 78-93. doi:http://dx.doi.org/10.1016/j.jcat.2010.11.017.

[10] J. Macht, R.T. Carr, E. Iglesia, Functional assessment of the strength of solid acid catalysts, J. Catal. 264 (2009) 54-66. doi:http://dx.doi.org/10.1016/j.jcat.2009.03.005.

[11] A.J. Jones, R.T. Carr, S.I. Zones, E. Iglesia, Acid strength and solvation in catalysis by MFI zeolites and effects of the identity, concentration and location of framework heteroatoms, J. Catal. 312 (2014) 58-68. doi:http://dx.doi.org/10.1016/j.jcat.2014.01.007.

[12] A.J. Jones, E. Iglesia, The Strength of Brønsted Acid Sites in Microporous Aluminosilicates, ACS Catal. 5 (2015) 5741-5755. doi:10.1021/acscatal.5b01133.

[13] D.J. Parrillo, C. Lee, R.J. Gorte, D. White, W.E. Farneth, Comparison of the Acidic Properties of H-[Al]ZSM-5, H-[Fe]ZSM-5, and H-[Ga]ZSM-5 Using Microcalorimetry, Hexane Cracking, and Propene Oligomerization, J. Phys. Chem. 99 (1995) 8745-8749. doi:10.1021/j100021a046.

[14] J. Macht, M.J. Janik, M. Neurock, E. Iglesia, Catalytic Consequences of Composition in Polyoxometalate Clusters with Keggin Structure, Angew. Chemie Int. Ed. 46 (2007) 7864-7868. doi:10.1002/anie.200701292.

[15] W.E. Garwood, CONVERSION OF C2-C10 TO HIGHER OLEFINS OVER SYNTHETIC ZEOLITE ZSM-5, Acs Symp. Ser. 218 (1983) 383-396.

[16] L.R. Martens, J.P. Verduijn, G.M. Mathys, The development of an environmental friendly catalytic system for the conversion of olefins, Catal. Today. 36 (1997) 451-460. doi:10.1016/s0920-5861(96)00236-2.

[17] S. Bessell, D. Seddon, The conversion of ethene and propene to higher hydrocarbons over ZSM-5, J. Catal. 105 (1987) 270-275.

[18] S. Svelle, S. Kolboe, O. Swang, Theoretical investigation of the dimerization of linear alkenes catalyzed by acidic zeolites, J. Phys. Chem. B. 108 (2004) 2953-2962. doi:10.1021/jp0371985.

[19] P. Oliveira, P. Borges, R.R. Pinto, M. Lemos, F. Lemos, J.C. Vedrine, et al., Light olefin transformation over ZSM-5 zeolites with different acid strengths - A kinetic model, Appl. Catal. a-General. 384 (2010) 177-185. doi:10.1016/j.apcata.2010.06.032.

[20] C. Tuma, J. Sauer, Protonated Isobutene in Zeolites: tert-Butyl Cation or Alkoxide?, Angew. Chemie. 117 (2005) 4847-4849. doi:10.1002/ange.200501002.

[21] J. Hajek, J. Van der Mynsbrugge, K. De Wispelaere, P. Cnudde, L. Vanduyfhuys, M. Waroquier, et al., On the stability and nature of adsorbed pentene in Brønsted acid zeolite H-ZSM-5 at $323 \mathrm{~K}$, J. Catal. 340 (2016) 227-235. doi:http://dx.doi.org/10.1016/j.jcat.2016.05.018.

[22] A. Bhan, Y. V Joshi, W.N. Delgass, K.T. Thomson, DFT Investigation of Alkoxide Formation from Olefins in H-ZSM-5, J. Phys. Chem. B. 107 (2003) 10476-10487. doi:10.1021/jp034382h.

[23] Y. Chu, B. Han, A. Zheng, X. Yi, F. Deng, Pore Selectivity for Olefin Protonation Reactions Confined inside Mordenite Zeolite: A Theoretical Calculation Study, J. Phys. Chem. C. 117 (2013) 2194-2202. doi:10.1021/jp311264u.

[24] G. Spoto, S. Bordiga, G. Ricchiardi, D. Scarano, A. Zecchina, E. Borello, IR STUDY OF 
ETHENE AND PROPENE OLIGOMERIZATION ON H-ZSM-5 - HYDROGENBONDED PRECURSOR FORMATION, INITIATION AND PROPAGATION MECHANISMS AND STRUCTURE OF THE ENTRAPPED OLIGOMERS, J. Chem. Soc. Trans. 90 (1994) 2827-2835. doi:10.1039/ft9949002827.

[25] F. Geobaldo, G. Spoto, S. Bordiga, C. Lamberti, A. Zecchina, Propene oligomerization on H-mordenite: Hydrogen-bonding interaction, chain initiation, propagation and hydrogen transfer studied by temperature-programmed FTIR and UV-VIS spectroscopies, J. Chem. Soc. Trans. 93 (1997) 1243-1249. doi:10.1039/a607052c.

[26] R. Gounder, A.J. Jones, R.T. Carr, E. Iglesia, Solvation and acid strength effects on catalysis by faujasite zeolites, J. Catal. 286 (2011) 214-223.

[27] D.A. Simonetti, R.T. Carr, E. Iglesia, Acid strength and solvation effects on methylation, hydride transfer, and isomerization rates during catalytic homologation of $\mathrm{C} 1$ species, $\mathrm{J}$. Catal. 285 (2010) 19-30.

[28] S. Grimme, J. Antony, S. Ehrlich, H. Krieg, A consistent and accurate ab initio parametrization of density functional dispersion correction (DFT-D) for the 94 elements H-Pu, J. Chem. Phys. 132 (2010) -. doi:http://dx.doi.org/10.1063/1.3382344.

[29] S. Grimme, S. Ehrlich, L. Goerigk, Effect of the damping function in dispersion corrected density functional theory, J. Comput. Chem. 32 (2011) 1456-1465. doi:10.1002/jcc. 21759.

[30] X. Liu, J. Klinowski, Gallosilicate zeolite catalysts: structural features of [Si,Ga]-ZSM-5, J. Phys. Chem. 96 (1992) 3403-3408. doi:10.1021/j100187a041.

[31] R. de Ruiter, J.C. Jansen, H. van Bekkum, Synthesis of Microporous Materials, in: M.L. Occelli, H.F. Robson (Eds.), Synth. Microporous Mater., Vol. 1, Van Nostrand Reinhold, New York, 1992: p. 167.

[32] S.A.I. Barri, D. Young, Crystalline zincosilicate, (1984).

[33] W.J. Ball, S.A.I. Barri, D. Young, Improved method of preparing crystalline aluminosilicates, (1986).

[34] C.M. White, J. Hackett, R.R. Anderson, S. Kail, P.S. Spock, Linear temperature programmed retention indices of gasoline range hydrocarbons and chlorinated hydrocarbons on cross-linked polydimethylsiloxane, J. High Resolut. Chromatogr. 15 (1992) 105-120. doi:10.1002/jhrc.1240150211.

[35] L. Soják, G. Addová, R. Kubinec, A. Kraus, G. Hu, Gas chromatographic-mass spectrometric characterization of all acyclic C5-C7 alkenes from fluid catalytic cracked gasoline using polydimethylsiloxane and squalane stationary phases, J. Chromatogr. A. 947 (2002) 103-117. doi:http://dx.doi.org/10.1016/S0021-9673(01)01564-3.

[36] G. Kresse, J. Hafner, Ab initio, Phys. Rev. B. 47 (1993) 558-561. doi:10.1103/PhysRevB.47.558.

[37] G. Kresse, J. Hafner, Itextit $\{\mathrm{Ab}$ initio $\}$ molecular-dynamics simulation of the liquidmetal \char21 \{\} amorphous-semiconductor transition in germanium, Phys. Rev. B. 49 (1994) 14251-14269. doi:10.1103/PhysRevB.49.14251.

[38] G. Kresse, J. Furthmüller, Efficiency of ab-initio total energy calculations for metals and semiconductors using a plane-wave basis set, Comput. Mater. Sci. 6 (1996) 15-50. doi:http://dx.doi.org/10.1016/0927-0256(96)00008-0.

[39] G. Kresse, J. Furthmüller, Efficient iterative schemes for \textit \{ab initio\} total-energy calculations using a plane-wave basis set, Phys. Rev. B. 54 (1996) 11169-11186. doi:10.1103/PhysRevB.54.11169. 
[40] P.E. Blöchl, Projector augmented-wave method, Phys. Rev. B. 50 (1994) 17953-17979. doi:10.1103/PhysRevB.50.17953.

[41] G. Kresse, D. Joubert, From ultrasoft pseudopotentials to the projector augmented-wave method, Phys. Rev. B. 59 (1999) 1758-1775. doi:10.1103/PhysRevB.59.1758.

[42] B. Hammer, L.B. Hansen, J.K. Nlorskov, Improved adsorption energetics within densityfunctional theory using revised Perdew-Burke-Ernzerhof functionals, Phys. Rev. B. 59 (1999) 7413-7421. doi:10.1103/PhysRevB.59.7413.

[43] J.P. Perdew, K. Burke, M. Ernzerhof, Generalized Gradient Approximation Made Simple, Phys. Rev. Lett. 77 (1996) 3865-3868. doi:10.1103/PhysRevLett.77.3865.

[44] Y. Zhang, W. Yang, Comment on "Generalized Gradient Approximation Made Simple", Phys. Rev. Lett. 80 (1998) 890. doi:10.1103/PhysRevLett.80.890.

[45] J.P. Perdew, J.A. Chevary, S.H. Vosko, K.A. Jackson, M.R. Pederson, D.J. Singh, et al., Atoms, molecules, solids, and surfaces: Applications of the generalized gradient approximation for exchange and correlation, Phys. Rev. B. 46 (1992) 6671-6687.

[46] J. Macht, R.T. Carr, E. Iglesia, Consequences of Acid Strength for Isomerization and Elimination Catalysis on Solid Acids, J. Am. Chem. Soc. 131 (2009) 6554-6565. doi:10.1021/ja900829x.

[47] H.J. Monkhorst, J.D. Pack, Special points for Brillouin-zone integrations, Phys. Rev. B. 13 (1976) 5188-5192. doi:10.1103/PhysRevB.13.5188.

[48] G. Henkelman, H. Jónsson, A dimer method for finding saddle points on high dimensional potential surfaces using only first derivatives, J. Chem. Phys. 111 (1999).

[49] G. Henkelman, H. Jónsson, Improved tangent estimate in the nudged elastic band method for finding minimum energy paths and saddle points, J. Chem. Phys. 113 (2000).

[50] C.T. Campbell, J.R. V Sellers, Enthalpies and Entropies of Adsorption on Well-Defined Oxide Surfaces: Experimental Measurements, Chem. Rev. 113 (2013) 4106-4135. doi: $10.1021 / \mathrm{cr} 300329 \mathrm{~s}$.

[51] L. Baerlocher, C. McCusker, Database of Zeolite Structures, Database Zeolite Struct. (2013) http://www.iza-structure.org/databases/.

[52] M.L. Sarazen, E. Doskocil, E. Iglesia, Effects of Void Environment and Acid Strength on Alkene Oligomerization Selectivity, ACS Catal. (n.d.). doi:10.1021/acscatal.6b02128.

[53] S. Namuangruk, P. Pantu, J. Limtrakul, Investigation of ethylene dimerization over faujasite zeolite by the ONIOM method, Chemphyschem. 6 (2005) 1333-1339. doi: $10.1002 /$ cphc. 200500023.

[54] A. Corma, INORGANIC SOLID ACIDS AND THEIR USE IN ACID-CATALYZED HYDROCARBON REACTIONS, Chem. Rev. 95 (1995) 559-614. doi:10.1021/cr00035a006.

[55] M.T. Aronson, R.J. Gorte, W.E. Farneth, An infrared spectroscopy study of simple alcohols adsorbed on H-ZSM-5, J. Catal. 105 (1987) 455-468. doi:http://dx.doi.org/10.1016/0021-9517(87)90073-X.

[56] E. Yoda, J.N. Kondo, K. Domen, Detailed Process of Adsorption of Alkanes and Alkenes on Zeolites, J. Phys. Chem. B. 109 (2005) 1464-1472. doi:10.1021/jp047376+.

[57] W.O. Haag, R.M. Lago, P.B. Weisz, THE ACTIVE-SITE OF ACIDIC ALUMINOSILICATE CATALYSTS, Nature. 309 (1984) 589-591. doi: $10.1038 / 309589 \mathrm{a} 0$.

[58] E.L. First, C.E. Gounaris, J. Wei, C.A. Floudas, Computational characterization of zeolite porous networks: an automated approach, Phys. Chem. Chem. Phys. 13 (2011) 17339- 
17358. doi:10.1039/C1CP21731C.

[59] P.B. Weisz, C.D. Prater, Interpretation of Measurements in Experimental Catalysis, in: V.I.K. and E.K.R.B.T.-A. in C. W.G. Frankenburg (Ed.), Academic Press, 1954: pp. 143 196. doi:http://dx.doi.org/10.1016/S0360-0564(08)60390-9.

[60] W.O. Haag, R.M. Lago, P.B. Weisz, Transport and reactivity of hydrocarbon molecules in a shape-selective zeolite, Faraday Discuss. Chem. Soc. 72 (1981) 317-330. doi:10.1039/DC9817200317.

[61] L. Song, L.V.C. Rees, Frequency Response Measurements of Diffusion in Microporous Materials BT - Adsorption and Diffusion, in: H.G. Karge, J. Weitkamp (Eds.), Springer Berlin Heidelberg, Berlin, Heidelberg, 2008: pp. 235-276. doi:10.1007/3829_2007_013.

[62] T. Masuda, Y. Okubo, S.R. Mukai, M. Kawase, K. Hashimoto, A. Shichi, et al., Effective diffusivities of lighter hydrocarbons in $\mathrm{Cu}$ - and Co-MFI-type zeolite catalysts, Chem. Eng. Sci. 56 (2001) 889-896. doi:http://dx.doi.org/10.1016/S0009-2509(00)00302-X.

[63] J.N. Kondo, S. Liqun, F. Wakabayashi, K. Domen, IR study of adsorption and reaction of 1-butene on H-ZSM-5, Catal. Letters. 47 (1997) 129-133. doi:10.1023/A:1019096703066.

[64] G. Sastre, V. Fornes, A. Corma, On the Preferential Location of Al and Proton Siting in Zeolites: A Computational and Infrared Study, J. Phys. Chem. B. 106 (2002) 701-708. doi: $10.1021 / \mathrm{jp} 013189 \mathrm{p}$.

[65] S. Sklenak, J. Dedecek, C. Li, B. Wichterlova, V. Gabova, M. Sierka, et al., Aluminium siting in the ZSM-5 framework by combination of high resolution 27Al NMR and DFT/MM calculations, Phys. Chem. Chem. Phys. 11 (2009) 1237-1247. doi:10.1039/B807755J.

[66] O. Kresnawahjuesa, G.H. Kühl, R.J. Gorte, C.A. Quierini, An Examination of Brønsted Acid Sites in H-[Fe]ZSM-5 for Olefin Oligomerization and Adsorption, J. Catal. 210 (2002) 106-115. doi:http://dx.doi.org/10.1006/jcat.2002.3657.

[67] P. Deshlahra, R.T. Carr, E. Iglesia, Ionic and Covalent Stabilization of Intermediates and Transition States in Catalysis by Solid Acids, J. Am. Chem. Soc. 136 (2014) 1522915247. doi:10.1021/ja506149c.

[68] P. Deshlahra, E. Iglesia, Toward More Complete Descriptors of Reactivity in Catalysis by Solid Acids, ACS Catal. 6 (2016) 5386-5392. doi:10.1021/acscatal.6b01402.

[69] R.T. Carr, M. Neurock, E. Iglesia, Catalytic consequences of acid strength in the conversion of methanol to dimethyl ether, J. Catal. 278 (2011) 78-93.

doi:10.1016/j.jcat.2010.11.017. 


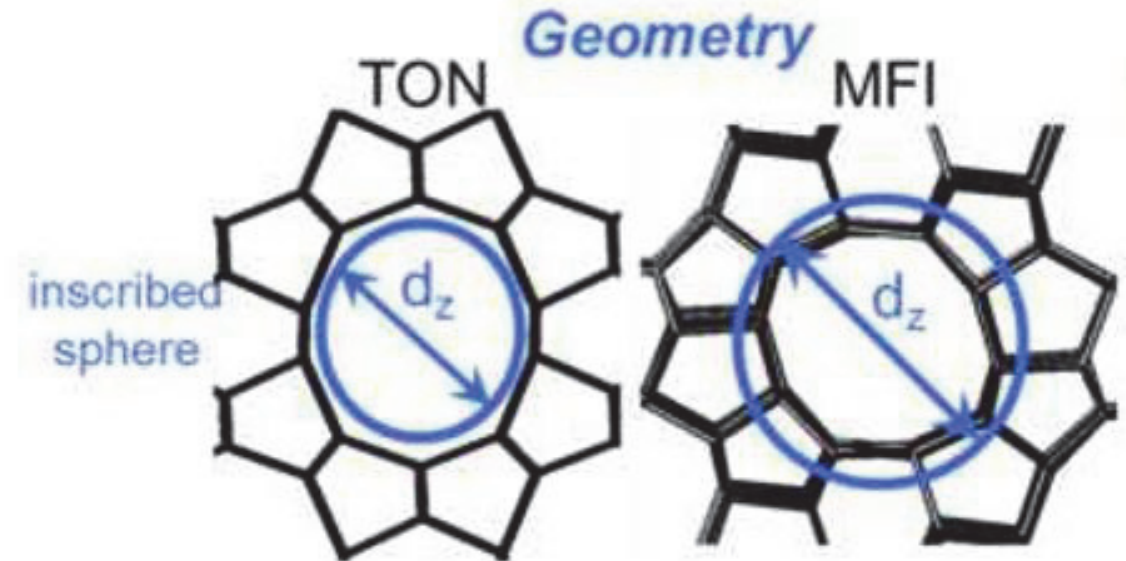

Transition States

van der Waals

diameter

conjugate

anion

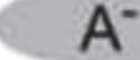

Reactivity descriptors: conjugate anion stability, proton affinity of organic moiety and van der Waals energy van der Waals

energy

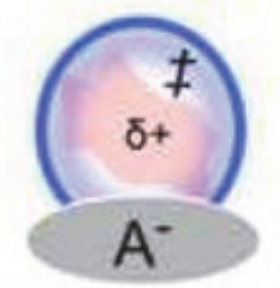

propene/TON

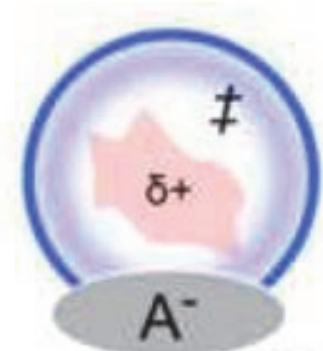

propene/MFI
Alkene Dimerization on Solid Acids

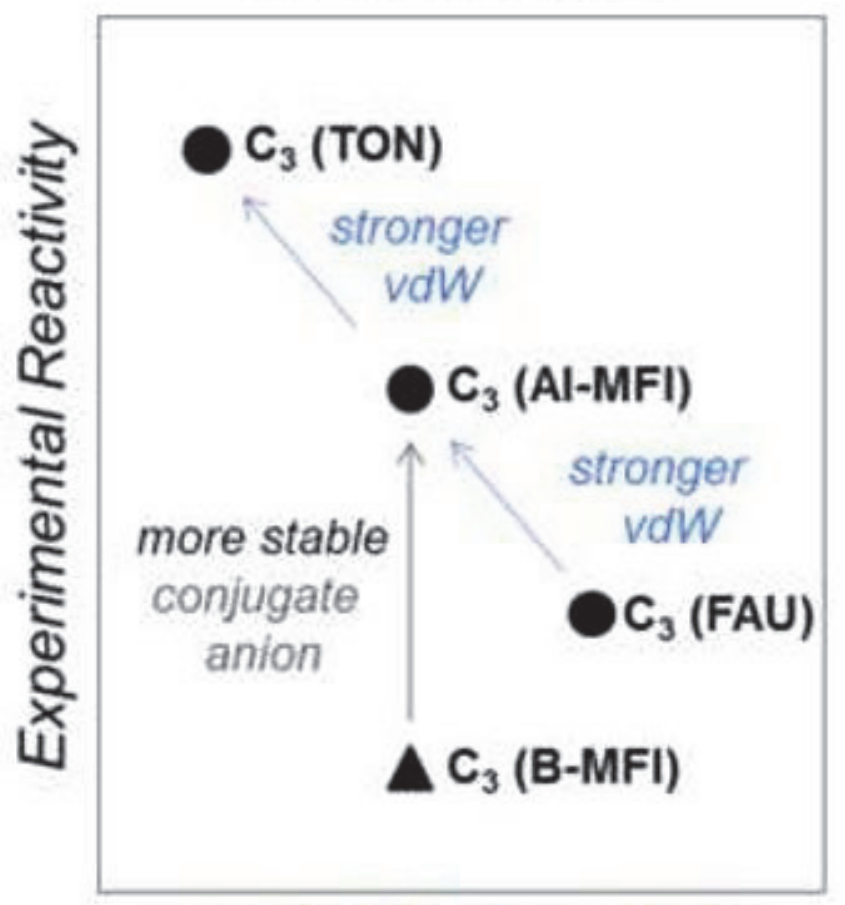

van der Waals energies 


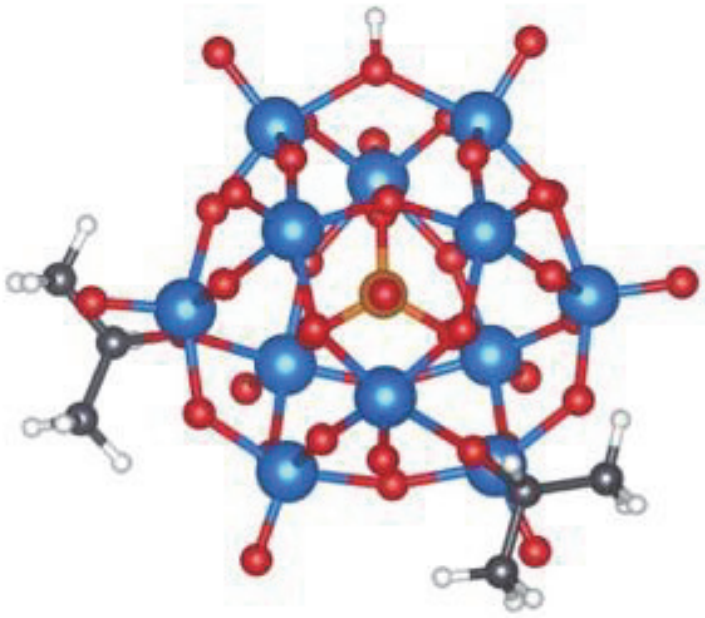






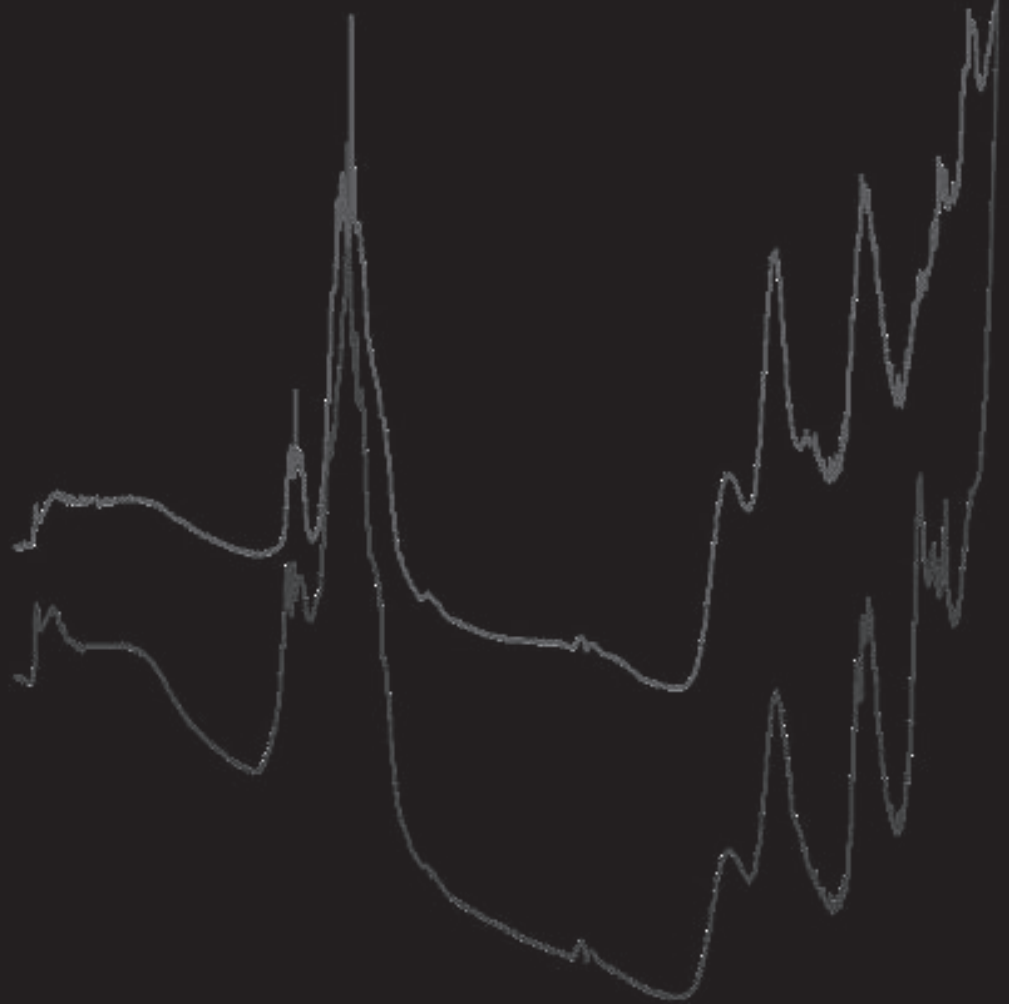




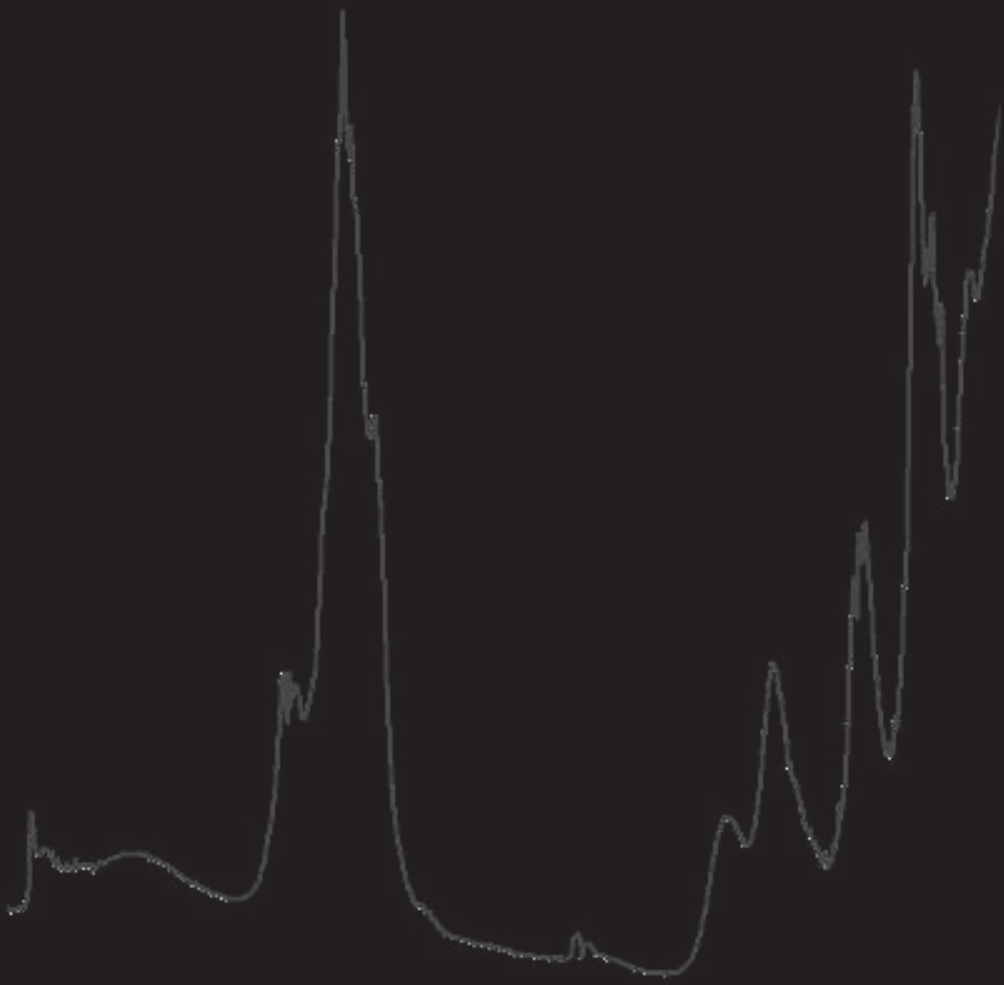



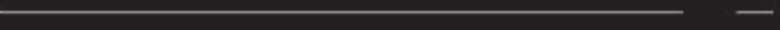

$-$

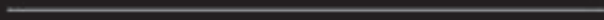

-

$\longrightarrow$
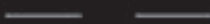

$\underline{\square}$

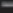

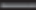




\section{$\mathrm{C}-\mathrm{C}$ bond formation}

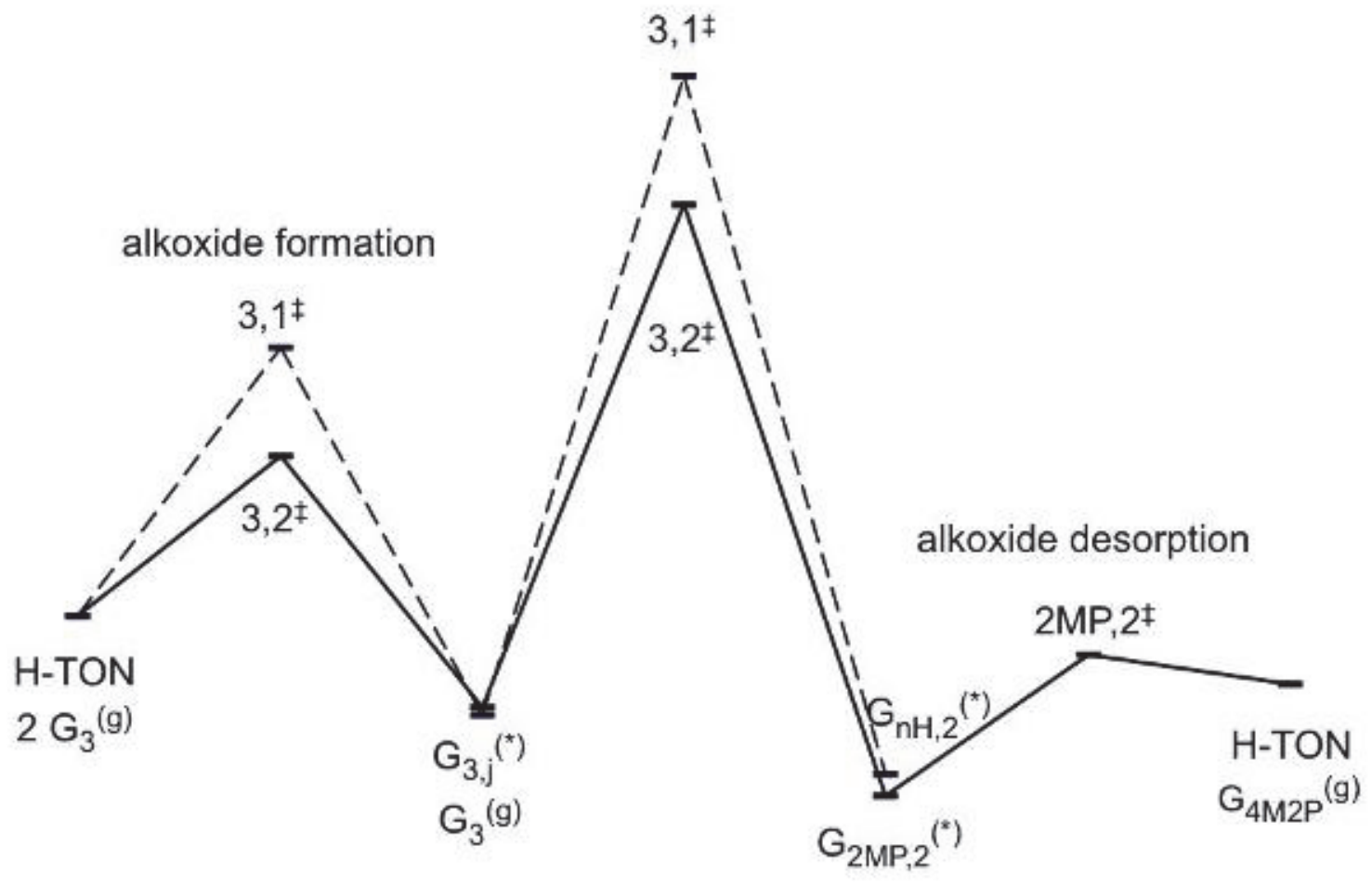






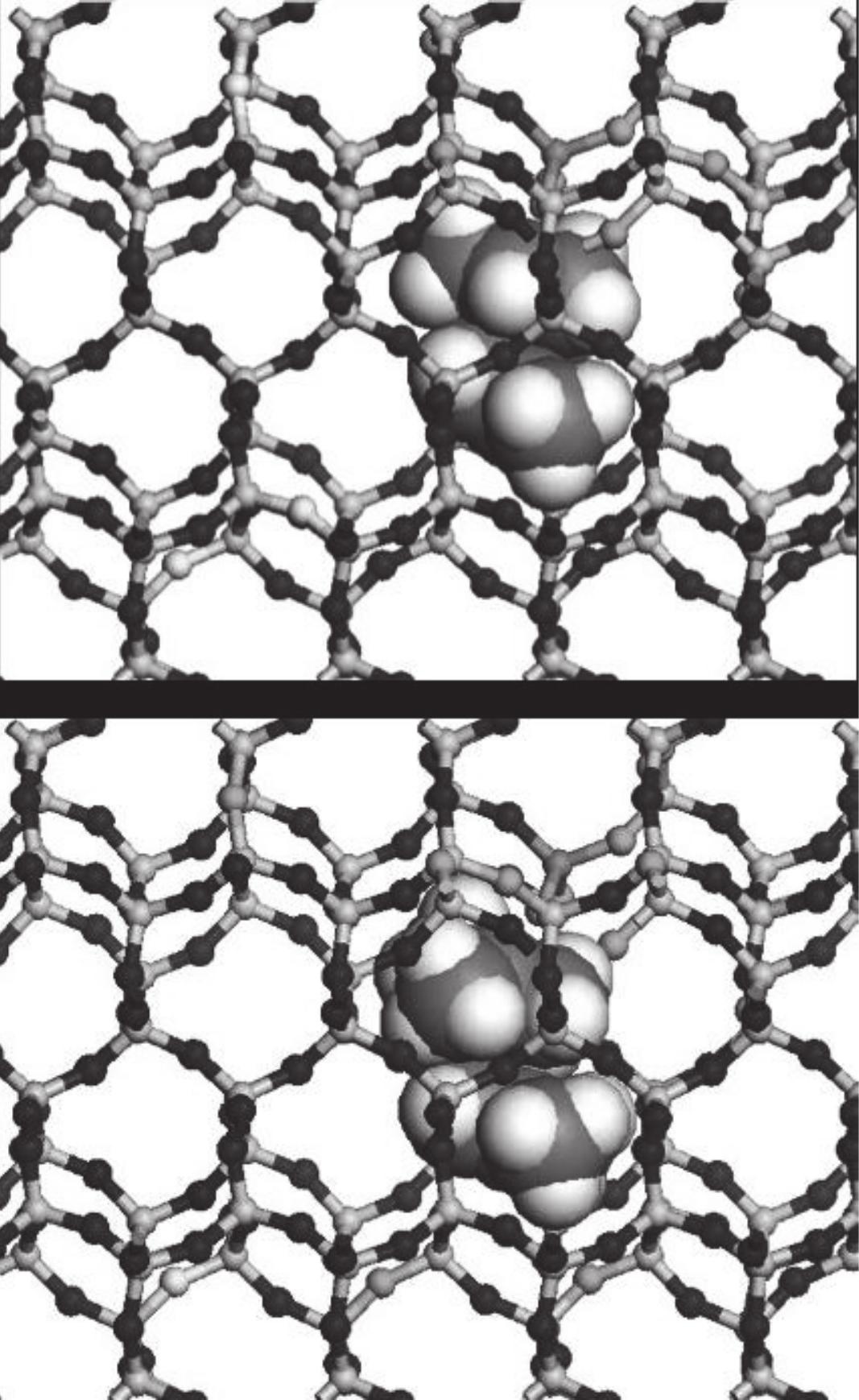

